\title{
Shallow Convection and Precipitation over the Southern Ocean: A Case Study during the CAPRICORN 2016 Field Campaign
}

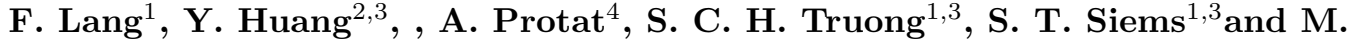 \\ J. Manton ${ }^{1}$ ${ }^{2}$ School of Earth Sciences, The University of Melbourne, Victoria, Australia.
${ }^{3}$ Australian Research Council Centre of Excellence for Climate Extremes, Australia. ${ }^{4}$ Australian Bureau of Meteorology, Victoria, Australia. \\ ${ }^{1}$ School of Earth, Atmosphere and Environment, Monash University, Victoria, Australia.
}

Key Points:

- Observations under open mesoscale cellular convection over the Southern Ocean are characterized by precipitation followed by cold pools

- Ice multiplication processes were likely to be active in the open mesoscale cellular convection clouds

- WRF simulations show only weak decoupling of the boundary layer, which might be associated to an SST bias in the initial boundary conditions

Corresponding author: Francisco Lang, francisco.lang@monash.edu

This article has been accepted for publication and ${ }^{-1}$ undergone full peer review but has not been through the copyediting, typesetting, pagination and proofreading process, which may lead to differences between this version and the Version of Record. Please cite this article as doi: 10.1029/2020JD034088.

This article is protected by copyright. All rights reserved. 


\begin{abstract}
Marine boundary layer clouds and precipitation observed in a sustained period of open mesoscale cellular convection (MCC) over the Southern Ocean (SO) are investigated using CAPRICORN 2016 observations, Himawari-8 products and numerical simulations. The shallow convection was characterized by the presence of supercooled liquid water and mixed-phase clouds in the sub-freezing temperature range, consistent with earlier in-situ observations where ice multiplication is found to be active in producing large quantities of ice in open MCC clouds. Ice-phase precipitation was observed to melt below cloud base with evidence of cold pools produced in a decoupled boundary layer. Convectionpermitting simulations using the Weather Research and Forecasting (WRF) model were able to reproduce many of the surface meteorological features and their evolution. However, the evolution of the boundary layer height and the degree of decoupling were poorly simulated, along with the absence of cold pools. The observed cloud morphology and microphysical characteristics were also not well reproduced in the control simulation with the Thompson microphysics scheme, where too much supercooled water was simulated in a too homogenous cloud field. Sensitivity experiments with modified microphysical parameters led to a higher production of glaciated clouds and precipitation. Sensitivity experiments with different boundary layer schemes and vertical resolution, however, showed a smaller impact. A bias of $\sim 4^{\circ} \mathrm{C}$ in the initial boundary conditions of the sea surface temperature is discussed. This study highlights the challenge of representing the complex physical processes that underpin the cloud, precipitation, and boundary layer characteristics of the open MCC over the SO.
\end{abstract}

\title{
1 Introduction
}

Mid- and high-latitude oceans are commonly covered by extensive areas of marine atmospheric boundary layer (MABL) clouds. Over the Southern Ocean (SO), these clouds are a fundamental component of the regional energy budget (Trenberth \& Fasullo, 2010), and their precipitation is a major component of the regional water budget. The processes that govern the formation and life cycle of precipitation, however, are poorly understood (e.g., Huang et al., 2017) and they contribute to large uncertainties in a range of precipitation estimate products (Behrangi et al., 2012, 2014).

Passive satellite observations show that marine boundary layer clouds commonly self-organize into mesoscale cellular convection (MCC). Based on the level of cellularity and mesoscale organization, MCC clouds can be categorized into four general categories: organized open MCC, organized closed MCC, homogeneous cloud sheets without cellularity on the mesoscale (no MCC) and inhomogeneous disorganized cells (Wood, 2012). The type of MCC is important as it modulates the overall cloud fraction and albedo, as well as microphysical properties such as precipitation rate, cloud droplet number concentrations $\left(N_{d}\right)$ and effective radius, affecting the radiation balance and precipitation efficiency of these clouds (Wood \& Hartmann, 2006; Wood et al., 2011). Compared to closed MCC, open MCC clouds are commonly associated with heavier drizzle (e.g., Ahn et al., 2017; Comstock et al., 2004, 2007; Sharon et al., 2006; Stevens et al., 2005; H. Wang \& Feingold, 2009a, 2009b), less short-wave reflectance and more transmissivity (Muhlbauer et al., 2014).

A satellite-based climatology of MCC clouds (Muhlbauer et al., 2014) suggests that the mid-latitude $\left(40-60^{\circ} \mathrm{S}\right) \mathrm{SO}$ is dominated by an open MCC cloud regime in austral winter, occurring up to $50 \%$ of the time. In contrast, a closed MCC regime is dominant nearly all year round over the high-latitude SO. Satellite observations have shown that the open MCC regime is commonly located in the post-frontal (e.g., Ahn et al., 2017), cold sector of mid-latitude cyclones (e.g., Field \& Wood, 2007) and in large cold-air outbreaks over oceans (Atkinson \& Zhang, 1996; McCoy et al., 2017). Indeed, limited aircraft observations have revealed that open $\mathrm{MCC}$ cloud fields over the SO are commonly 
characterized by mixed-phase clouds and the frequent presence of drizzle/light precipitation (Ahn et al., 2017). Huang et al. (2017) used these aircraft observations to further demonstrate that ice multiplication (such as the Hallett-Mossop mechanism) may be active in producing large quantities of ice in these open MCC clouds, which were observed to be intermittently precipitating. Given that light precipitation accounts for $\sim 82 \%$ of the total precipitation fraction over the SO (Z. Wang et al., 2015), mixed-phase clouds, particularly those residing in the open MCC, may play an essential role in governing the precipitation processes in this region. At near-surface level, precipitation from open MCC commonly is associated with reduced temperatures or "cold pools", which have been found to be driven by the evaporation of precipitation in the subcloud layer for stratocumulus over the northeast Pacific (e.g., Stevens et al., 2005) and trade wind cumulus (e.g., Zuidema et al., 2012). Aircraft observations found that cold pools in the southeast Pacific are associated with heavy drizzle rates in open MCC, whereas those in the surrounding overcast regions cold pools are absent (Terai et al., 2014). This characteristic in precipitation from cumulus clouds over the SO was described by Jensen et al. (2000), where the development of precipitation in these clouds initiated cold pools at the surface. Evaporative cooling from precipitation decouples the subcloud layer, suppresses vertical mixing, and increases surface fluxes. Previous studies have also suggested that open MCC response to evaporative cooling from precipitation is essential in cloud formation and organization (Savic-Jovcic \& Stevens, 2008; H. Wang \& Feingold, 2009a).

Modelling studies, too, have examined various aspects of the mesoscale shallow convection over the oceans. Using large-eddy simulations (LES) that explicitly simulate the dominant scales of cloud-turbulence interaction, studies focusing on subtropical oceans have shown that precipitation from stratocumulus clouds is an important (if not the only) mechanism for the initiation of open MCC (e.g., H. Wang \& Feingold, 2009a, 2009b; Yamaguchi \& Feingold, 2015). LES simulations, however, simply remain too computationally expensive to simulate the full life cycle of these clouds, and with a horizontal grid spacing that is sufficiently small to resolve convective eddies explicitly, especially considering that open MCC over the SO can cover tens of thousands of square kilometers and last for a period of days. As such, despite the lack of explicitly resolved turbulent processes, numerical weather prediction (NWP) models configured at a convection-permitting mode appear to be an attractive tool to study some of the most important aspects of open MCC (e.g., Vincent et al., 2012).

Over the past decades, convection-permitting models have been widely used to study boundary layer clouds and precipitation over the SO (e.g., Huang et al., 2014; Huang, Franklin, et al., 2015; Morrison et al., 2010). Morrison et al. (2010) simulated mixedphase clouds off the coast of Tasmania and found that the difficulties in simulating clouds containing supercooled liquid water (SLW) lie, in part, in the inability of the reanalysis products employed for model initialization to reproduce the wind shear and temperature inversion through the MABL. Models struggle to simulate SLW in low-topped shallow convective clouds because many microphysical parameterization schemes underestimate the presence of SLW when ice is present, where ice growth is at the expense of liquid water depletion (e.g., Field et al., 2014; Tan \& Storelvmo, 2016).

The main objective of the present study is to examine an open MCC case over the SO using unique shipborne measurements and satellite observations during the Clouds, Aerosols, Precipitation, Radiation, and atmospherIc Composition Over the southeRn oceaN (CAPRICORN) field experiment in 2016. The focus is to understand the nature of the precipitation generated from a sustained period of open MCC between 25 and 27 March 2016 in a post-frontal environment, and the accompanying boundary layer thermodynamics. These open MCC were characterized by the presence of mixed-phase clouds and relatively heavy precipitation. It is worth noting that this case study is one of the first with a set of collocated surface and remote-sensing observations, whereas previous studies of precipitation from open MCC have been limited to aircraft observations (e.g., Abel 
et al., 2017; Ahn et al., 2017; Terai et al., 2014). The observations are then used to evaluate the Weather Research and Forecasting (WRF) model in simulating these clouds and to understand the potential causes of model deficiencies via sensitivity experiments. This detailed study allows us to raise fundamental questions over this region regarding the role of open MCC and ice multiplication processes in enhancing intensity of surface precipitation in this region and to examine their representation in convection-permitting models.

\section{Observations and Synoptic Situation}

\subsection{Shipborne Observations}

The 2016 CAPRICORN voyage took place aboard of the Australian Marine National Facility (MNF) Research Vessel (R/V) Investigator. From 13 March to 15 April 2016, the R/V Investigator traversed the SO from south of Tasmania, covering an area of $43-53^{\circ} \mathrm{S}$ and $141-151^{\circ} \mathrm{E}$ (Fig. 1a). Table 1 provides a summary of observational data used in this study. Additional information on the instrumentation deployed is available in Mace and Protat (2018b, 2018a). Cloud phase is produced by merging information obtained from the cloud radar and lidar aboard the R/V Investigator (Fig 2a). First, the cloud top, cloud base and phase are determined using the lidar backscatter and depolarization data, following the method in Alexander and Protat (2018). Ice and liquidcloud phases are determined by considering the relationship between layer-integrated depolarization ratio and backscatter as in $\mathrm{Hu}$ et al. (2010). The cloud radar is then used to refine the cloud phase categories. The mixed-phase category is determined from the presence or absence of a detectable cloud radar signal for lidar pixels classified as "SLW". When there is no detectable cloud radar signal, the classification remains SLW; if there is a detected cloud radar signal, these pixels are reclassified as "mixed-phase". A similar simple approach is used for CloudSat-CALIPSO cloud phase detection (Delanoë \& Hogan, 2010). When the cloud radar detects a signal at subfreezing temperatures, but the lidar is fully attenuated by lower cloud layers and therefore does not provide any information on cloud phase, the pixel is assigned as "mixed-phase or ice". This category is left non-definitive since there is not enough information to separate the two. A more detailed description of this radar-lidar merged product and a comparison with CALIPSO can be found in Noh et al. (2019).

The primary objectives of CAPRICORN were to (i) characterize the cloud, aerosol, and precipitation properties, boundary layer structure, biological production and cycling of dimethyl sulfide (DMS) in the upper ocean, atmospheric composition, and surface energy budget, as well as their latitudinal variability; (ii) evaluate and improve satellite estimations of these properties; and (iii) evaluate and improve the representation of these properties in the regional and global versions of the Australian Community Climate and Earth-System Simulator (ACCESS) model.

\subsection{Satellite Products}

High-resolution Himawari-8 cloud products provided by the Australian Bureau of Meteorology (BoM) are also used, including the cloud-top phase and the cloud-top temperature (hereafter CTP and CTT) retrievals. These cloud products are generated by the BoM using the GOES-R Advanced Baseline Imager (ABI) Cloud Height Algorithm (ACHA; Heidinger, 2011) developed at the National Oceanic and Atmospheric Administration (NOAA) and the National Environmental Satellite, Data, and Information Service (Pavolonis, 2010). Using the multichannel information provided by the Advanced Himawari Imager (AHI), the ACHA combines the 13.3- $\mu \mathrm{m} \mathrm{CO}_{2}$ absorption channel coupled with the longwave infrared windows $10.4,11.2$, and $12.4 \mu \mathrm{m}$, to derive cloud-top height and CTT information simultaneously with cloud microphysics information. The CTP product is derived from four AHI infrared channels (7.3, 8.6, 11.2, and $12.4 \mu \mathrm{m})$. 


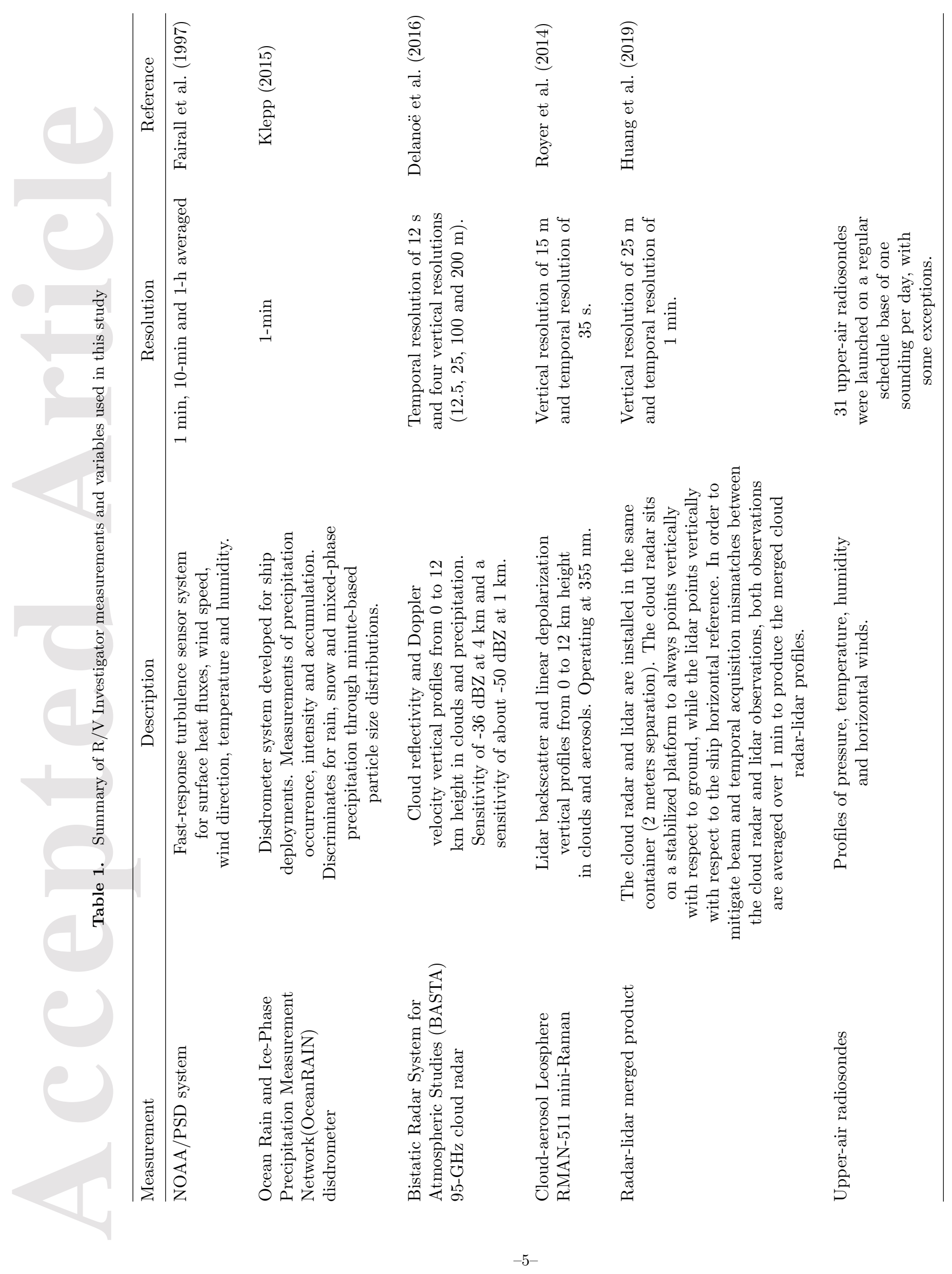


For Himawari-8, CTT and CTP are retrieved at a spatial resolution of $2 \mathrm{~km}$ and a temporal resolution of $10 \mathrm{~min}$ (day and night). A more detailed description and initial evaluations of these products can be found in Huang et al. (2019).

The identification of open and closed MCC clouds is performed by visual inspection of the Himawari- 8 cloud products for the complete period of study, according to the organizational features of the cloud morphology.

\subsection{Synoptic Meteorology}

The sampling period of 25 to 27 March 2016 was characterized by a cold front crossing Tasmania, passing over the ship on 25 March (Fig. 1b). After the frontal system passed, the region experienced cold-air advection in a southwesterly flow, leaving a sustained period of open MCC over the ship and the surrounding ocean (Fig. 1c). Immediately following the frontal passage, a non-precipitation period was observed, which transitioned into a period of open MCC clouds. The latter condition was maintained for approximately 36 hours between 0600 UTC on 26 March up to 1730 UTC on 27 March, before a stratocumulus cloud field (closed MCC) started to dominate the region, as observed by Himawari8. Our primary focus is on the open MCC period.

\section{Methodology}

\subsection{Sounding Analysis}

Upper-air radiosondes are used to examine the thermodynamic structure of the MABL, including the identification of the inversion and boundary layer decoupling. The inversion height is defined as the height of maximum gradient in the virtual potential temperature profile, $d \theta_{v} / d z$, between 100 and $5000 \mathrm{~m}$ above sea level, with a minimum gradient threshold of $0.01 \mathrm{~K} \mathrm{~m}^{-1}$ to define an inversion as significant [see Hande et al. (2012) and Lang et al. (2018) for more details]. As a feature of boundary layer decoupling, the presence of a transition layer is identified using the technique of Yin and Albrecht (2000), which is determined from the parameter $\mu$ defined as,

$$
\mu=-\left(\frac{\delta \theta}{\delta P}-\frac{0.608 \theta}{1+0.608 r} \frac{\delta r}{\delta P}\right),
$$

where $r$ is mixing ratio and $\theta$ is potential temperature. This parameter attempts to identify the presence of a transition layer for each level below the main inversion by considering the effects of the gradients of both $\theta$ and $r$. Decoupling is diagnosed when (1) the maximum value of $\mu$ is positive, and (2) it extends over all levels below the inversion base at which $\mu$ is greater than 1.3 times its average from the surface to the inversion base. We tested the sensitivity of $\mu$ and found that the threshold of 1.3, which was used in Yin and Albrecht (2000), captured the transition layers reasonably well.

\subsection{Experimental Design of Numerical Simulations and Sensitivity Ex- periments}

The Advanced Research WRF (ARW, version 3.9.1) employed in this study is based on non-hydrostatic Euler equations, designed for both mesoscale atmospheric research and operational forecasting needs (Skamarock et al., 2008). In this work, the model is configured with an outer domain and three one-way nested domains, which were applied with a horizontal spacing of $27,9,3$, and $1 \mathrm{~km}$ (Fig. 1a) and with $64 \eta$-levels. The outer domain covers a broad area of the SO between approximately $35^{\circ}$ and $60^{\circ} \mathrm{S}$, and the first nested domain incorporated Tasmania and its surrounding oceans. The two inner domains are centered to capture the ship track during the simulation period. The initial and lateral boundary conditions in all experiments were derived from the European Cen- 
tre for Medium-Range Weather Forecasts (ECMWF) ERA-Interim reanalysis $\left(0.75^{\circ} \times\right.$ $0.75^{\circ}$ grid, 37 pressure levels, and 6-hourly updates) (Dee et al., 2011). The simulation is initialized at 0000 UTC 25 March 2016 and run for a period of $72 \mathrm{~h}$. A 12-h spin-up period is used to prevent any noisy outputs during the period of model stabilization. For the control (Ctrl) simulation, the configuration is based on the optimal setting in previous WRF simulations over Tasmania and the SO as in Huang et al. (2014) and Z. Wang et al. (2016). This configuration included the Rapid Radiative Transfer Model for GCMs (RRTMG) shortwave and longwave radiation scheme (Iacono et al., 2008; Mlawer et al., 1997), the Noah land surface model (Chen \& Dudhia, 2001), Yonsei University (YSU; Hong et al., 2006) planetary boundary layer scheme and the Simplified Arakawa-Schubert (SAS) cumulus scheme (Pan \& Wu, 1995), which is used only on the two coarsest domains $(27$ and $9 \mathrm{~km}$ ). For the control simulation, the 2008 Thompson semi-double-moment bulk microphysics scheme (Thompson et al., 2008) is used. This scheme is a double-moment (prognostic mass and number concentrations) for ice and rain and single-moment (prognostic mass concentration only) for other species (i.e., snow, graupel, cloud water, and water vapor).

A suite of sensitivity simulations was undertaken to investigate the impact of the model representation of boundary layer and microphysical processes on the simulations of the open MCCs and their precipitation.

\subsubsection{Planetary Boundary Layer (PBL) Experiment}

The MABL structure over the SO determines the organization of shallow convection, particularly when decoupling occurs (Jones et al., 2011). However, the SO MABL structure has been found to be biased in reanalysis data sets (e.g., Lang et al., 2018) and climate models (e.g., Williams et al., 2013). Thus, the aim of this experiment is to examine the sensitivity of the simulations to different PBL schemes where the unresolved turbulent vertical fluxes of momentum, heat, and constituents such as moisture within the boundary layer are parameterized. Three PBL schemes are tested: the YSU scheme, Mellor-Yamada-Janjic (MYJ; Mellor \& Yamada, 1982) scheme and the asymmetric convective model, version 2, (ACM2; Pleim, 2007). The MYJ scheme is a local closure model, while the YSU and ACM2 schemes are non-local models.

\subsubsection{Microphysics (MP) Experiment}

Bulk parameterization of ice cloud microphysics is particularly challenging due to the complexity of ice processes. The Thompson et al. (2008) scheme uses the Cooper parameterization (Cooper, 1986), where ice initialization is dependent on temperature. By default, the Thompson scheme applies the Cooper parameterization when liquid saturation is reached below $253.15 \mathrm{~K}$ (or the relative humidity with respect to ice exceeds $125 \%$ ). Secondary ice particles are generated via the rime-splinter or Hallet-Mossop process. The splinter production rate is assumed to peak at a temperature of $-5^{\circ} \mathrm{C}$ and linearly decreases toward $-3^{\circ}$ and $-8^{\circ} \mathrm{C}$ as in Reisner et al. (1998). We investigated the impacts of changing the primary ice nucleation temperature on the simulated cloud microphysics, where two warmer temperatures -10 and $0^{\circ} \mathrm{C}$ are tested. The Thompson scheme uses a prescribed cloud droplet number concentration $\left(N_{d}\right), 100 \mathrm{~cm}^{-3}$ over the ocean, which is consistent with the recent summertime observations during the Southern Ocean Clouds Radiation Aerosol Transport Experimental Study (SOCRATES) (Y. Wang et al., 2020; McFarquhar et al., 2020). However, Ahn et al. (2017) analyzed the cloud data from 20 flights in the open ocean around Tasmania during winter over three years (2013-2015) and found that the open MCC sampling showed a mean value of $21 \mathrm{~cm}^{-3}$, similar to previous findings over the SO (e.g., Bennartz, 2007; Boers, 1995; Boers et al., 1998). Such range of the $N_{d}$ observed necessitates an additional sensitivity experiment with a reduced $N_{d}$ of $25 \mathrm{~cm}^{-3}$. 


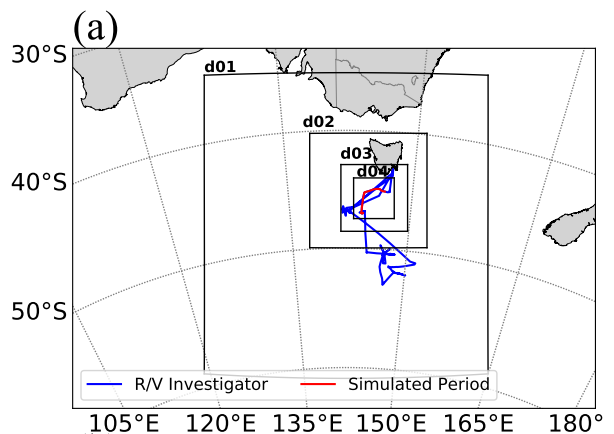

(b)

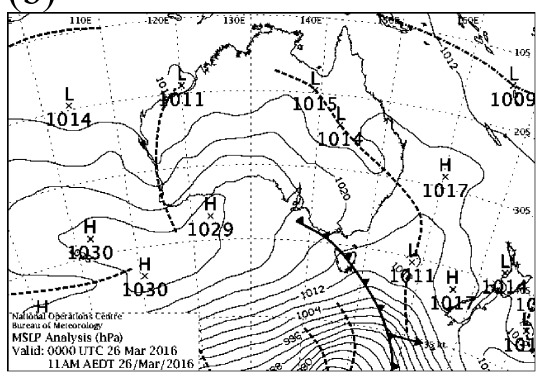

(c)

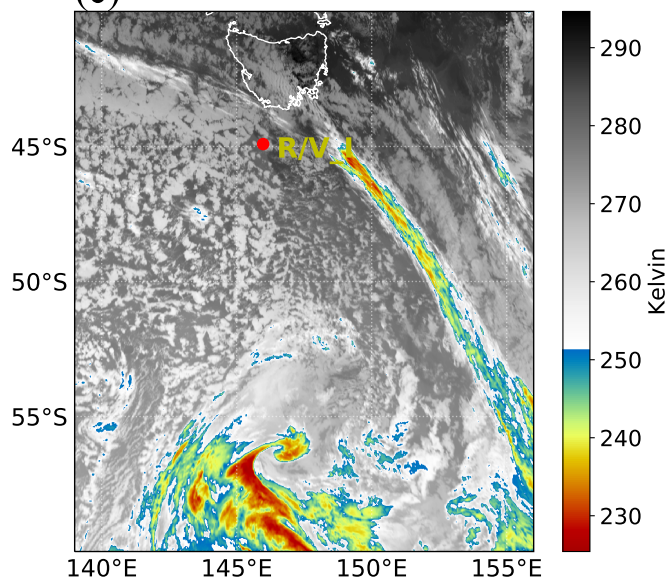

Figure 1. (a) Map showing the WRF domains with R/V Investigator track, (b) mean sealevel pressure analyses at 0000 UTC 26 March 2016, and (c) Himawari-8 geostationary satellite channel 13 at 0000 UTC on 26 March 2016. 
Table 2. A list of configuration settings for sensitivities studies.

\begin{tabular}{|c|c|c|c|c|}
\hline Nomenclature & PBL scheme & MP scheme & Vertical resolution & Modification \\
\hline Control (Ctrl) & YSU & Thompson & Default $64 \eta$-level & - \\
\hline PBL-1 & MYJ & Thompson & Default $64 \eta$-level & - \\
\hline PBL-2 & ACM2 & Thompson & Default $64 \eta$-level & - \\
\hline MP-1 & YSU & Thompson & Default $64 \eta$-level & $\begin{array}{l}\text { Temperature at start of } \\
\text { ice nucleation }=263 \mathrm{~K}\end{array}$ \\
\hline MP-2 & YSU & Thompson & Default $64 \eta$-level & $\begin{array}{l}\text { Temperature at start of } \\
\text { ice nucleation }=273 \mathrm{~K}\end{array}$ \\
\hline MP-3 & YSU & Thompson & Default $64 \eta$-level & $N_{d}=25 \mathrm{~cm}^{-3}$ \\
\hline VR & YSU & Thompson & Modified $64 \eta$-level & $\begin{array}{l}\text { Homogenization of the } \\
\text { levels within the MABL. }\end{array}$ \\
\hline
\end{tabular}

\subsubsection{Vertical Resolution (VR) Experiment}

The vertical levels in the model are configured as in (Huang et al., 2014), which include $64 \eta$-levels with 21 levels within the lowest kilometer. However, observations (presented in Section 4.1.1) show that low-level clouds were present primarily between 1 and $2 \mathrm{~km}$ in this case. To examine the effect of the vertical resolution in the cloud simulations, we modified the vertical resolution by adding new levels and changing the vertical spacing between them within the cloud layer. Table 2 .

A summary of the sensitivity experiments undertaken in this study is provided in

\subsubsection{Sea Surface Temperature and Fluxes Biases}

The sea surface temperature (SST) for ERA-Interim, ERA5 and the Modern-Era Retrospective analysis for Research and Applications, Version 2 (MERRA-2) are biased between March 22 and March 262016 for the study region, with a sudden increase of $\sim 6^{\circ} \mathrm{C}$ on March 22 (Fig. S1 in supporting information). Bharti et al. (2019) notes that no ship observations of SST and dependent surface fluxes were available from 22-26 March due to ship maintenance. At this time the SST instrument had been pulled from the ocean and was on the deck of the ship, inadvertently producing biased observations (Fig. S1) Unfortunately, these errant SST observations are evident in the reanalysis products.

This warmer bias will increase the difference between SST and air temperature, which might lead to a stronger net surface heat flux. Previous numerical studies have demonstrated that an increase in the surface latent heat flux (LHF) as response to a warmer SST plays an important role in generating a systematic decoupling (e.g., Bretherton \& Wyant, 1997; Sandu \& Stevens, 2011).

\section{Results}

\subsection{Precipitation, Cloud Structure and Microphysics Observed}

The CAPRICORN 2016 observations of this case study allow us to raise a fundamental question about the importance of open MCC ice processes in enhanced intensity of surface precipitation over this region. To better understand the potential role of the ice in precipitation from open MCCs, we first examine shipborne observations and retrievals of low-level mixed-phase clouds. 


\subsubsection{Shipborne Measurements}

The thermodynamic phase of the precipitation in the shallow convection is well characterized by the Radar-lidar merged product (Fig. 2a), where the observed cloud field was present primarily below $2.5 \mathrm{~km}$. The phase classification shows that these clouds are predominantly mixed phase, with patches of SLW between regions of uncertain classification (i.e. mixed or ice phase). The lidar depolarization ratio was used to determine the phase of precipitation at cloud base (Fig. 2b), following the methodology described in Mace and Protat (2018b). Critical thresholds for liquid- and ice-phase layers were chosen to be $\leq 0.02$ and $\geq 0.03$, respectively. To identify these thresholds, Mace and Protat (2018b) examined the distributions of the lidar depolarization ratio for layers that were certainly liquid and layers that were certainly ice phase. No ice layers were found to have a depolarization ratio of less than 0.03 during CAPRICORN campaign. Cloud layers with ratios between 0.02 and 0.03 were classified as ambiguous and were not assigned as a specific phase. A detailed description of the threshold definitions and associated uncertainties is discussed in Appendix B of Mace and Protat (2018a). The lidar depolarization ratios near cloud base suggest that the precipitating ice was intermittently detected at heights above the freezing level throughout the open MCC period.

The lidar deporalization ratio and Radar-lidar phase classification at cloud base have an agreement of $72 \%$ during both open and closed MCC periods. In a sensitivity test (not shown) with the lidar depolarization threshold set to 0.05 , the agreement between the two phase classifications was found to be $73 \%$. The presence of ice in the radarlidar merged product and the common presence of precipitating ice by lidar depolarization ratio in the open MCC suggest that ice processes may be closely linked to the development of precipitation. While both phase classifications suffer from inherent uncertainties and limitations, an additional source of evidence can be observed in the Doppler vertical velocities from the radar (Fig. S2, in supporting information). Figure S2 shows a 12-hour example during the open MCC period, where a sharp transition in Doppler vertical velocities at about $1.2 \mathrm{~km}$ height is observed, consistent with the radar reflectivity, which indicates the presence of ice above and melted ice below. Doppler vertical velocity is not included in the manuscript because the cloud radar was not mounted on a stabilized platform yet during this field campaign.

Time series of observed temperature, relative humidity and precipitation from the ship show that the cold front passed the ship between 1400 UTC on 25 March and 0600UTC on 26 March (Fig. 2a). The frontal precipitation had a peak rate of $2.5 \mathrm{~mm} \mathrm{~h}^{-1}(1 \mathrm{~min}$ resolution) and a total accumulation of $16.5 \mathrm{~mm}$, before the launch of the first radiosonde at 2157 UTC on 25 March. After the frontal band passed the ship, the temperature dropped by $5{ }^{\circ} \mathrm{C}$ and the relative humidity dropped from $\sim 80 \%$ to $\sim 60 \%$ until 0700 UTC on 26 March. The wind speed decreased as well, while the surface wind direction changed from northwest to southwest and then remained westerly through the rest of the open MCC period (Fig. 2c). A cloud-free non-precipitating slot immediately after the frontal passage is observed, until approximately 0800 UTC on 26 March, when the disdrometer started to detect precipitation (liquid phase only) generated by the open MCC clouds at notably higher rates $\left(5.9 \mathrm{~mm} \mathrm{hr}^{-1}\right.$ peak), compared to the frontal precipitation. Figure 2e shows the time series of reflectivity profiles from the Radar-lidar merged product, where it is possible to observe cloud-free areas and intermittent open MCC clouds with high reflectivities ( $>10 \mathrm{dBZ}$ ) associated with precipitation that reached the sea surface, as observed by the disdrometer. $95 \%$ of the heavy precipitation, defined as $>1.5 \mathrm{~mm} \mathrm{hr}^{-1}$ over the SO (Z. Wang et al., 2015; Lang et al., 2020), is associated with profiles of mixed- or icephase clouds. The disdrometer measures the particle diameter for recorded precipitation. No significant differences are observed in the drop size distributions between the different periods. The heaviest precipitation from the open MCC clouds is associated to cloud-top heights between 2.7 and $2 \mathrm{~km}$ (Fig. 2a,d). The subsequent closed MCC cloud 
(a)
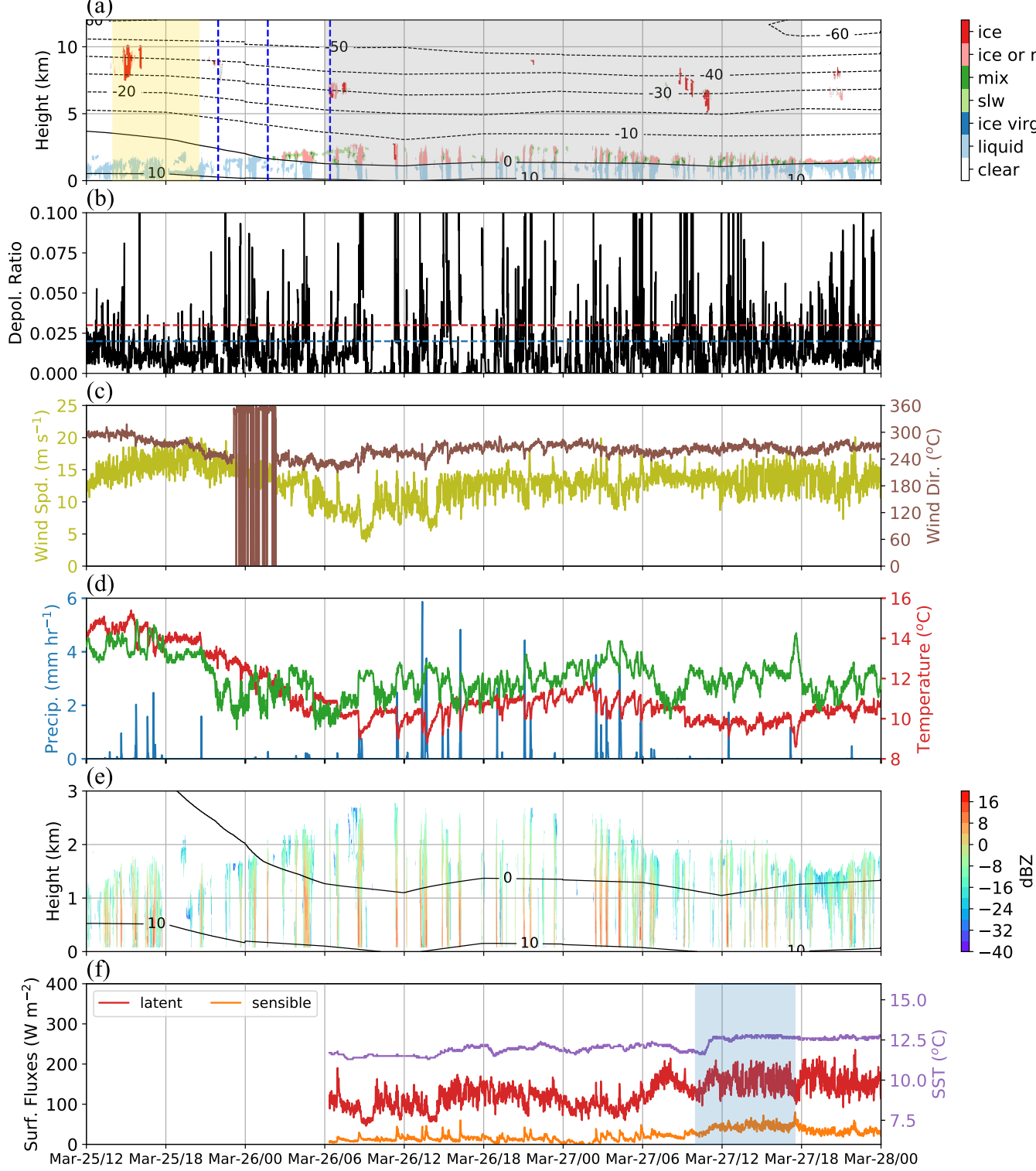

Figure 2. (a) Cross-section of the cloud-phase product. Dashed blue lines indicate the approximate launch time of the soundings. Yellow shaded area indicates the approximate time of the frontal passage and gray shaded area the open MCC period. (b) The lidar depolarization ratio at cloud base, values above 0.03 indicate the likely presence of ice phase precipitation at cloud base and below 0.02 indicate liquid phase. (c) Time series of surface level wind speed and wind direction. (d) Time series of surface level precipitation, temperature and relative humidity. (e) Cross-section of the radar reflectivity. (f) Time series of surface heat fluxes and SST, blue shaded area indicates the ship's passage from open to closed MCC. No fluxes and SST observations were available from 23 to 26 March due to ship maintenance. For Radar-lidar merged product (a) and (d), temperature contours are from ERA-Interim. Temporal resolution is $1 \mathrm{~min}$ for all panels. 
(a)
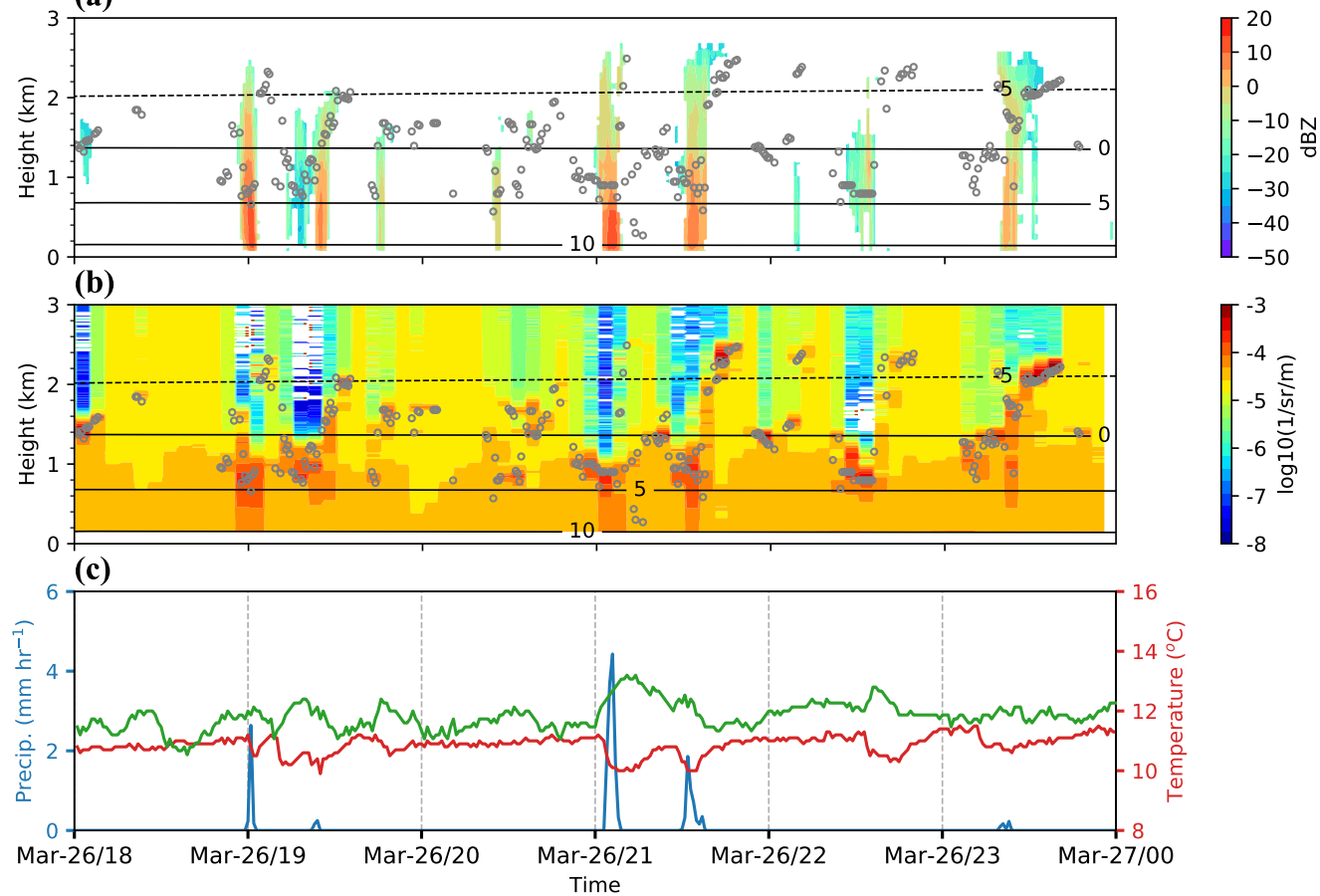

Figure 3. Subperiod during the open MCCs, (a) Cross-section of the radar reflectivity. (b) Cross-section of copolar lidarattenuated backscatter. Gray circles indicate lidar cloud base. (d) Time series of surface level precipitation, temperature and relative humidity.

field was below $2 \mathrm{~km}$ cloud-top height and the accumulated precipitation for the closed $\mathrm{MCC}$ at the end of the time series is minimal with $0.55 \mathrm{~mm}$.

During the period of open MCC, a consistent relationship between precipitation and the thermodynamics measured on the ship is evident. From roughly 0800 UTC on 26 March, the occurrence of peak rain rates (Fig. 2d) and high radar reflectivity in the open MCC (Fig. 2e) are associated to periods of decreased air temperature and increased relative humidity (e.g., 1300, 1600, 2100 UTC on 26 March). Indeed, during the 36-hour open MCC period, the temperature drops (about $0.6^{\circ} \mathrm{C}$ ) are recorded $34 \%$ of the time, coinciding with the precipitation as observed by the disdrometer and/or the cloud radar. A shorter 6-hr period is shown in Fig. 3 to illustrate a more detailed thermodynamic structure and surface observations of the open MCC clouds, which includes the copolar lidar backscatter and cloud base height (Fig 3b). Both the lidar and the radar observations (Fig. 3a,b) show two distinct layers of cloud, the lower layer at $\sim 1 \mathrm{~km}$ as observed at 21:00 UTC and the upper layer at $\sim 2.5 \mathrm{~km}$ at 21:40 UTC, which are thermodynamically decoupled. The cold pools are commonly observed for $\sim 50-110 \mathrm{~min}$ before the temperature returns to values typical of the rest of the surface layer. The strength of the observed cold pools are not directly correlated to the strength of observed precipitation, but that is not expected given the intermittent nature of shallow convection. These surface layer cold pools presumably affect the sensible heat flux (SHF) and LHF (Fig. 2f). The colder surface air temperature leads to an increase in SHF because the larger difference between sea surface temperature (SST) and air temperature. It also results in higher relative humidity, which reduces the evaporation and therefore LHF. Further, both temperature and SHF recovers faster to mean values than the relative humidity and LHF. The net surface heat flux is actually observed to be reduced during episodes of cold pools. 
(a) Observed Reflectivity

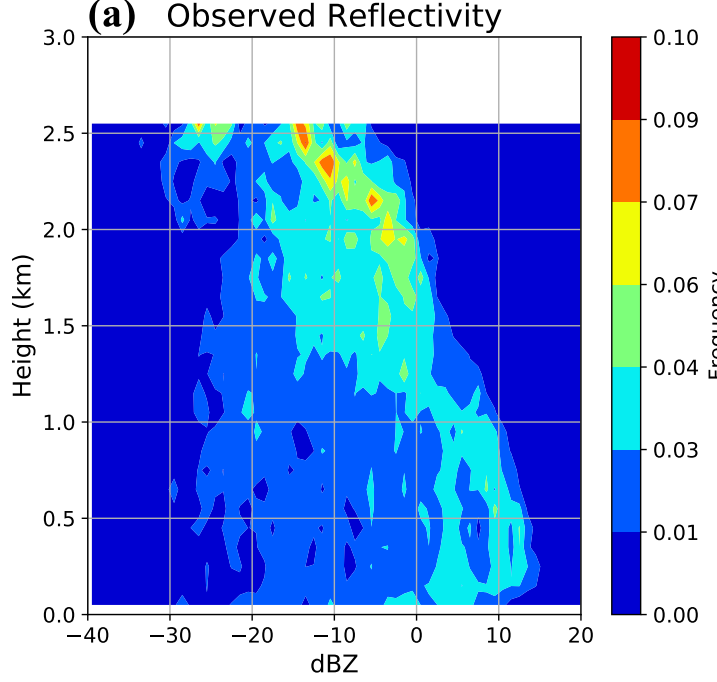

(b) Simulated Reflectivity

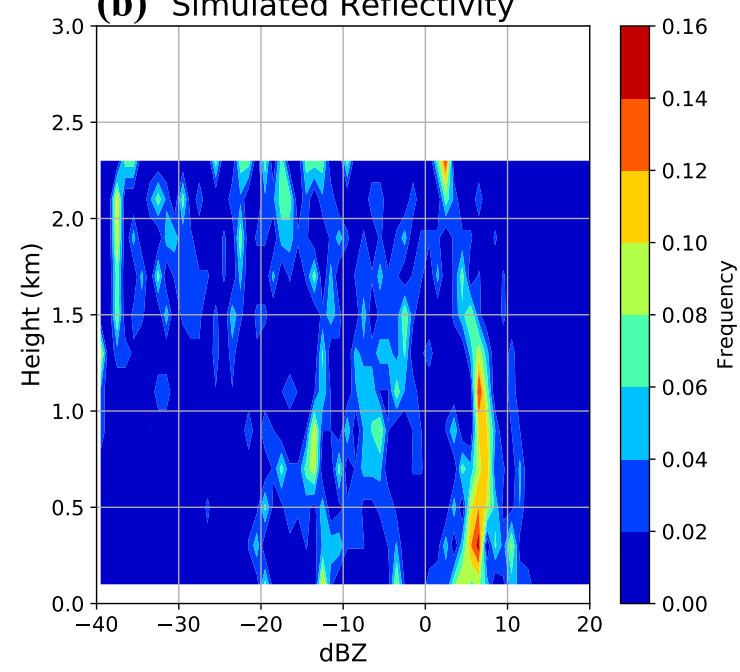

Figure 4. Contoured frequency with altitude (CFAD) diagrams for the open MCC period of (a) observed radar reflectivity (1-min resolution) and (b) simulated reflectivity with attenuation for the Ctrl simulation (30-min resolution).

The radar reflectivity for the open MCC period can be compiled into a vertical distribution plot known as contour frequency by altitude diagrams (CFAD, Fig 4a) (e.g., Huang, Protat, et al., 2015). In the upper branch, the reflectivity increases towards low altitudes, which reflects particles growing in size as they collect other particles. Evidence of a melting layer is identified near $1.1 \mathrm{~km}$, which corresponds to the transition from icephase precipitation (when $\mathrm{T}<0^{\circ} \mathrm{C}$, reflectivity $<5 \mathrm{dBZ}$ ) to warm precipitation (when $\mathrm{T}>0^{\circ} \mathrm{C}$, reflectivity $>5 \mathrm{dBZ}$ ), until reaching the maximum frequencies in range $2-2.6$ $\mathrm{km}$. This CFAD structure suggests the presence of ice in the observed shallow clouds.

The ship passed from open to closed MCC in the same post-frontal air mass between 1000 UTC and 1730 UTC on 27 March. Surface heat fluxes and SST (Fig. 2f) are observed to increase during this passage, the LHF increases from $\sim 123$ to $158 \mathrm{~W} \mathrm{~m}^{-2}$ and the SHF increases from $\sim 21$ to $33 \mathrm{~W} \mathrm{~m}^{-2}$, while the SST increases by $\sim 1^{\circ} \mathrm{C}$ at 1100 UTC. A temperature drop is observed as well, about $1^{\circ} \mathrm{C}$ colder than during the open MCC, increasing the air-sea temperature difference. Consistently heat fluxes become stronger during this passage and the subsequent closed MCC period. At this point, during the passage, precipitation is minimal.

Three upper-air soundings were launched after the front passed the ship (2157 UTC on 25 March, 0142 and 0624 UTC on 26 March, respectively), two of them during the non-precipitation period, and the last one at the beginning of the open MCC period (Fig. $2 \mathrm{a})$. Figure 5 shows the sounding profiles interpolated to the $64 \eta$-levels as in the numerical simulations, the vertical wind shear is simply defined as $\sqrt{\Delta U^{2}+\Delta V^{2}} / \Delta z$. For all soundings, mixing ratio profiles show that the turbulence was not able to maintain a single well-mixed layer throughout the boundary layer. The depth of the main inversion is observed to gradually grow from approximately $1.5 \mathrm{~km}$ to $2.4 \mathrm{~km}$ after the front passage, consistent with the climatological structure found in Lang et al. (2018). The transition layer is observed to reach a maximum height of $1.7 \mathrm{~km}$ at 0624 UTC. The three upper-air soundings and the Radar-lidar merged observations (Fig. 2a,e) exhibit evidence of decoupling, with the transition layer separating two distinct layers of clouds, a stratocumulus upper layer and a cumulus layer that was emanating probably from the surface- 
flux-driven turbulence. The temperature of the stratocumulus layer near the main inversion was about $-8.8^{\circ} \mathrm{C}$ at $0624 \mathrm{UTC}$ (third sounding).

\subsubsection{Satellite Data}

Retrieved cloud properties of Himawari-8, at 1000 UTC on 26 March 2016, are shown in Fig. 6a,b. The most immediate feature is a widespread open MCC cloud field over a region of cold-air advection in a southwesterly flow (Fig. 1c). Consistent with the time series of the shipborne Radar-lidar merged cloud-phase product (Fig. 2a), Himawari-8 shows an extensive field of open MCC dominated by supercooled and mixed-phase cloud tops at CTT below freezing, while ice phase was only occasionally present, primarily associated with the frontal clouds.

Examining the cloud-top phase properties, Fig. 7 shows the histogram of the relative frequencies of the CTP decomposed as a function of temperature for Himawari8 observations. This histogram is calculated following the ship-track across the full duration of the open MCC clouds. The histogram shows primarily CTT warmer than $-10^{\circ} \mathrm{C}$, consistent with the temperature profiles in Fig. 5. The peaks at warm temperatures (from $0^{\circ}$ to $10^{\circ} \mathrm{C}$ ) highlight the prevalence of primarily liquid boundary layer clouds, where the cumulative frequency of warm cloud tops is approximately $41 \%$. In temperature ranges between $0^{\circ} \mathrm{C}$ and $-5^{\circ} \mathrm{C}$, the relative frequency of liquid cloud tops decreases to $7 \%$, while the relative frequencies of SLW (13\%) and mixed-phase cloud tops (5\%) increase. The ice cloud tops, found below $-15^{\circ} \mathrm{C}(12 \%$ of the total cloud cover), and they are mainly associated with some cloudy remnants of the frontal passage at the beginning of the period and some patchy high-level cirrus in the post-frontal environment.

Himawari-8 observations show open MCC cloud-top heights located between 2100 and $1900 \mathrm{~m}$, and lower heights for the closed MCC period (1800 m average). As reported by Huang et al. (2019), cloud-top heights from Himawari-8 observations agree reasonably well with the Radar-lidar observations from CAPRICORN 2016. Fig 2 shows that cloud-top height for the open MCCs is in the range $2-2.7 \mathrm{~km}$, higher than the cloud-top height for the closed MCC which is mostly below $2 \mathrm{~km}$.

\subsection{Model Simulations}

The previous analysis in section 4.1 suggests that ice processes may be important for the development of precipitation in the open MCC and the subsequent cold pools. To test this hypothesis, numerical simulations including a set of sensitivity experiments were performed using a convection-permitting WRF model. To the extent the simulations reproduce reality, the relative importance of some microphysical processes and boundary layer dynamics will be explored.

\subsubsection{Control Simulation of Precipitation, Cloud Structure and Micro- physics}

Time series of observed winds, temperature, moisture and precipitation from the ship are directly compared to the WRF simulations (Fig. 8). The timing of the winds, temperature and moisture in the simulations is generally in good agreement with the observations. Both the temperature and specific humidity $(q)$ from the simulation and observations match reasonably well (Fig. 8c,d). The largest differences between the observed and simulated time series are in the precipitation (Fig. 8e,f). While the precipitation rates are overestimated during the frontal passages (March 25, 1400-1800 UTC), the simulation is able to reproduce the cloud-free slot right after the front. In the open MCC period, both simulated and observed accumulated precipitation are in the same range 4$4.5 \mathrm{~mm}$, but observed precipitation is more homogeneously distributed in time compared to the simulation, which appears to be spikier with a few high peaks. The simulated tem- 

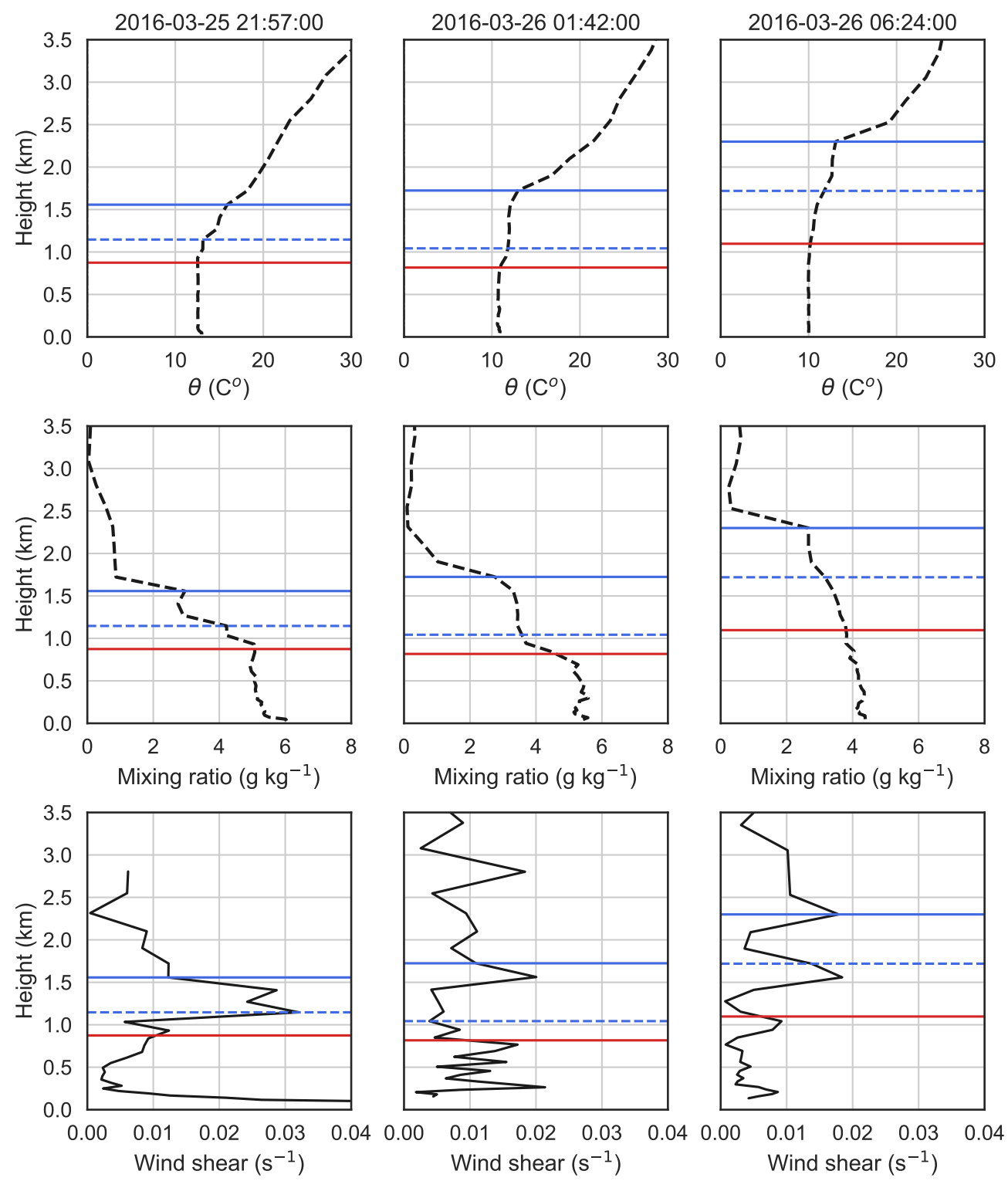

Figure 5. Thermodynamic profiles of potential temperature $(\theta)$, mixing ratio and wind shear obtained from shipborne upper-air soundings. Solid blue lines correspond to main inversion heights and dashed lines to transition layer heights. Solid red lines correspond to the lifting condensation level (LCL). The $\mu$ values for each transition layer are $4.7,0.6$ and $1.3 \mathrm{~K} \mathrm{hPa}^{-1}$, respectively. 

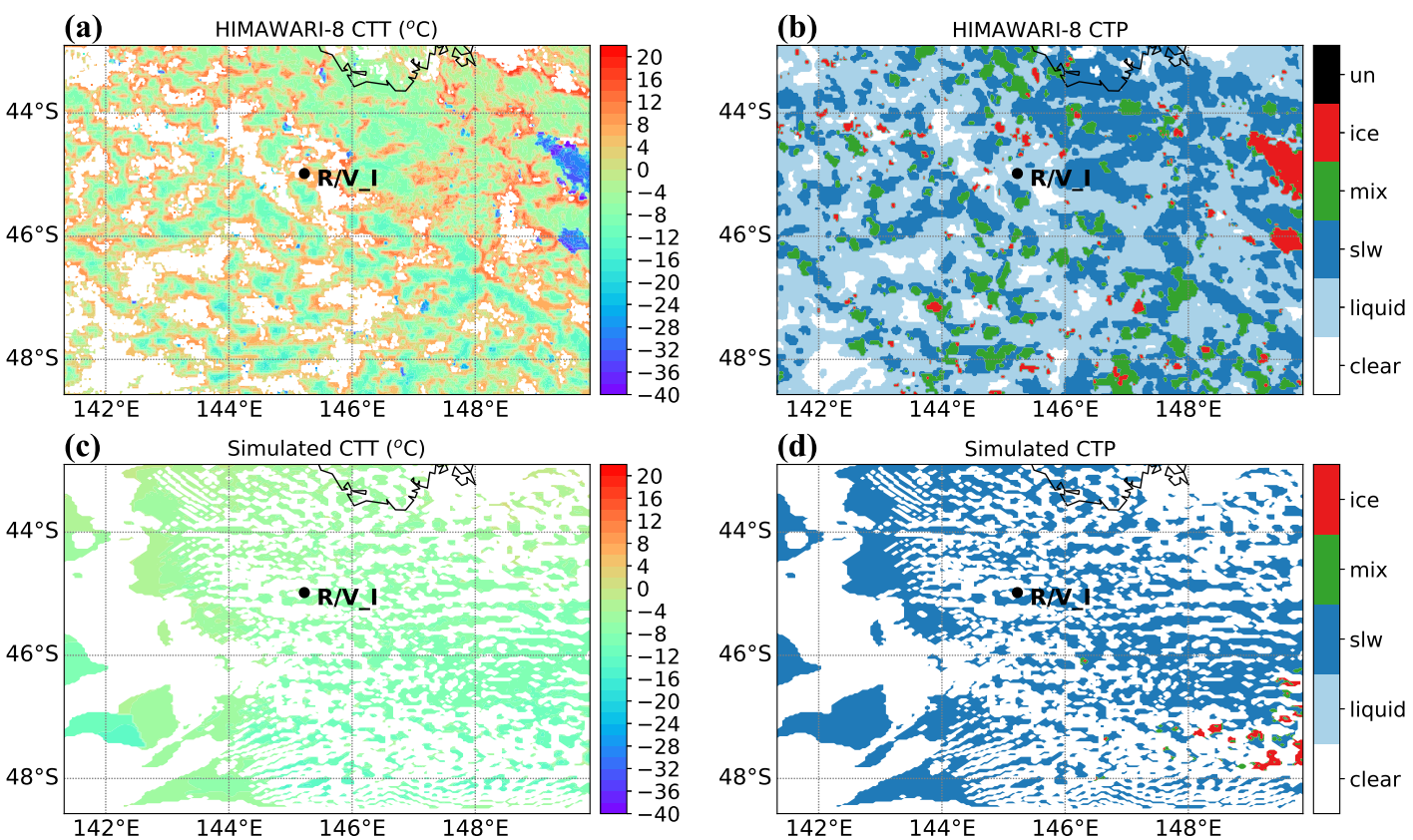

Figure 6. Himawari- 8 observations and control simulated cloud-top properties at 10:00 UTC on 26 March 2016. (a) Himawari-8 CTT, (b) Himawari-8 CTP, (c) Base simulated CTT, (d) Base simulated CTP. Black dots mark the location of the R/V Investigator. A simple diagnostic scheme [see Huang et al. (2014)] based on the relative fraction of liquid water to total water, and cloud top defined at 0.1 cloud optical thickness from the top of the model is applied to examine cloud-top properties.

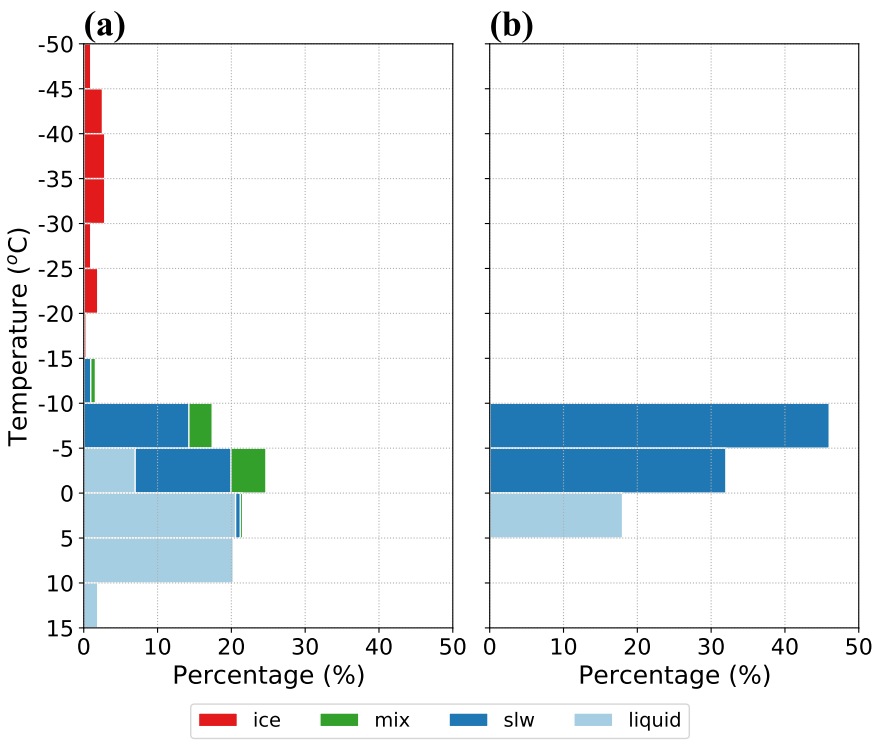

Figure 7. Histogram of relative frequencies of CTP (ice, mixed phase, SLW and liquid water) decomposed into $5^{\circ} \mathrm{C}$ temperature bins during the open MCC period for (a) Himawari-8 and (b) Ctrl simulation, following the ship-track across the full duration of the open MCC clouds. 
perature (Fig. 8c) is less variable and less correlated with the precipitation (Fig. 8e), with weaker signals of the cold pools in the Ctrl simulation compared to the observed. Simulated surface fluxes are shown in Fig. 8g,h. Both LHF and SHF are overestimated during the open MCC period until 1100 UTC on 27 March, then the SHF is underestimated until the end of this period. The LHF follows a decreasing path from the open to closed MCC periods. For the transition period from open to closed MCC, the simulated temperature and $q$ are able to capture the decreasing tendency during this transition (Fig. 8c,d). In contrast to the observed transition period, the simulated fluxes decrease, reaching a minimum during the closed MCC period at the end of the time series, yet the values match the observations. The Ctrl simulation continues to produce precipitation during the closed MCC period, whereas observations record little precipitation at that time. As mentioned above, the initial boundary conditions show that ERAInterim poorly captured SST, with a difference $\sim 4^{\circ} \mathrm{C}$ higher than observed at the beginning of the open MCC period and decreasing in time towards the closed MCC period (Fig. S1). This bias in the SSTs is reflected in the simulated SHF and LHF (Fig. 8g,h) through much of the first 48 hours of the simulation. The enhanced surface fluxes very likely affect the structure of the MABL including the strength of any decoupling and height of the inversion, but the extent of the impact is difficult to quantify.A model intercomparison study on simulations of stratocumulus-to-cumulus transition during a cold-air outbreak over the North Atlantic Ocean Tomassini et al. (2017) found that differences in surface fluxes not affect the qualitative behavior of the models in reproducing the boundary layer structures because not all models specified the same SSTs in their simulations, although the SST differences between the different models are $\sim 2{ }^{\circ} \mathrm{C}$ in their study, half of our simulation bias.

A direct comparison between radar observations and the simulations was implemented by using the radar simulator QuickBeam (Haynes et al., 2007), which outputs the simulated reflectivity using the simulated mixing ratios of the hydrometers (Fig. 4b). The simulated CFAD looks much patchier, with the absence of an ice-growing pattern in cloud and a melting layer. There is also a lack of simulated reflectivity greater than $10 \mathrm{dBZ}$ in the boundary layer. This comparison suggests that the Ctrl simulation underrepresents the ice processes in these shallow clouds. Time series of simulated reflectivity are included in the in supporting information (Fig. S3).

Figure 9 compares the soundings with the simulated profiles averaged from the 25 nearest grid points in the $1 \mathrm{~km}$ domain for the Ctrl simulation. The simulated profiles do not properly reproduce the main inversion heights in the first and third profiles, with heights of 2.1 and $2.0 \mathrm{~km}$ respectively. The transition layer is not evident in the first sounding, while for the second and third soundings this layer is at $1.2 \mathrm{~km}$ ( $\mu$ values 0.32 and $0.67 \mathrm{~K} \mathrm{hPa}^{-1}$, respectively). In general, the simulation is unable to reproduce the growth of the MABL height in the post-frontal air-mass as recorded by the three soundings. Further, the simulation overestimates the humidity within the boundary layer for all the soundings, especially in the first one, where the dewpoint is overestimated by $\sim 3^{\circ} \mathrm{C}$ and the moist layer height is $\sim 500 \mathrm{~m}$ deeper than observed (not shown). The decoupling in the boundary layer is not fully captured by the simulation. Instead, the humidity profiles suggest that the simulated MABL is generally more well mixed compared to the observed. It is noted that wind shear strength is underestimated in the simulations, which may be partly attributed to deficient wind shear in the lateral boundary conditions from ERAInterim (Fig. 9). The underrepresentation of cold pools could further correspond to the underrepresentation of decoupling in the simulations.

Figure 6 shows the simulated CTT and CTP from the Ctrl simulation at 1000 UTC on 26 March 2016. Simulated CTP and CTT are defined by Huang et al. (2014) diagnostic method, which is based on the relative fraction of liquid water to total water at 0.01 optical depth from cloud top. In contrast to the observed CTP, the simulated cloud tops are dominated by SLW, with little evidence of glaciation or mixed phase. The sim- 

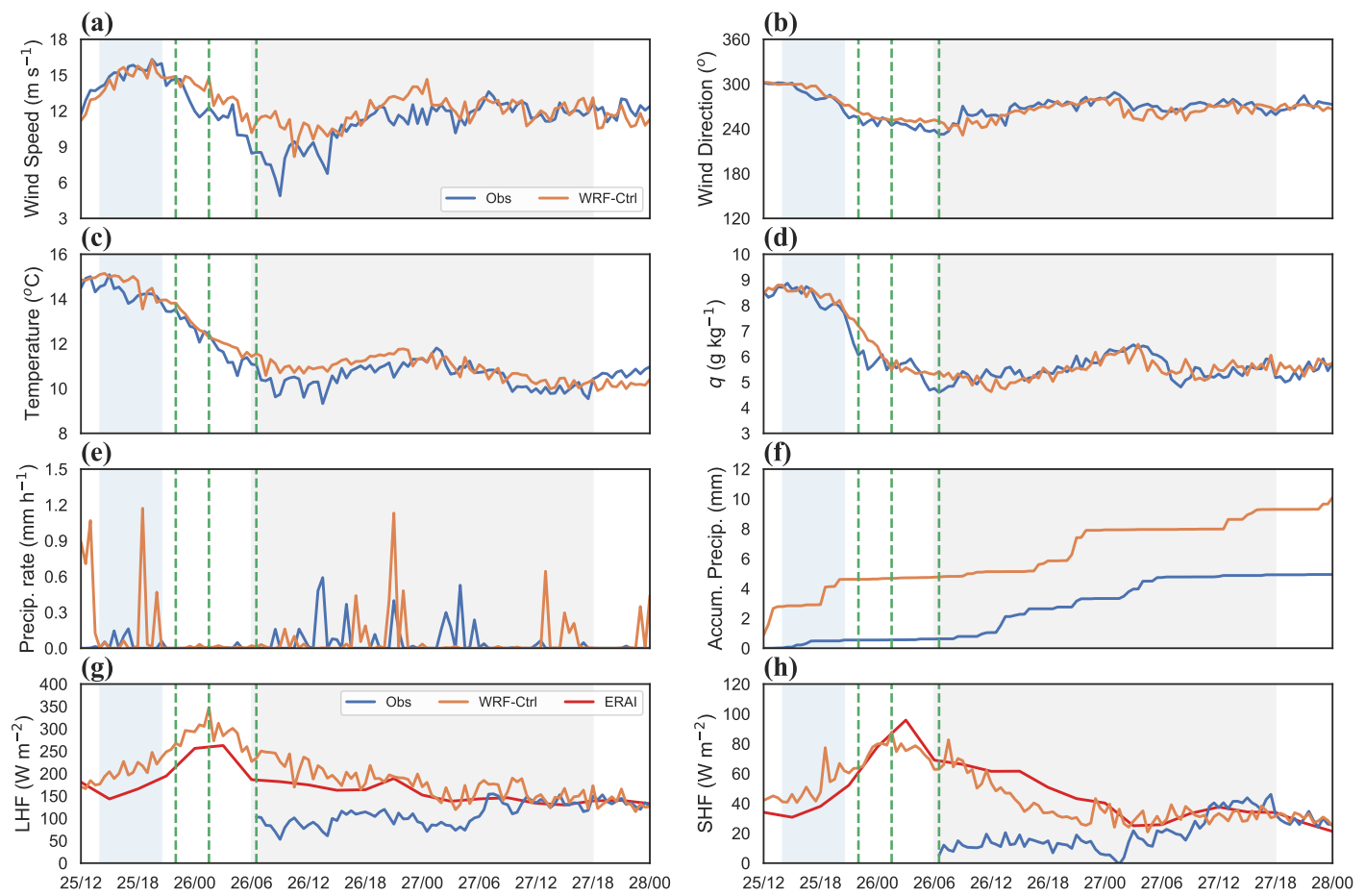

Figure 8. Time series of meteorological variables for shipborne observations and WRF Control simulation. The temporal resolution is $30 \mathrm{~min}$. (a) wind speed $\left(\mathrm{m} \mathrm{s}^{-1}\right)$, (b) wind direction $\left({ }^{\circ}\right)$, (c) air temperature $\left({ }^{\circ} \mathrm{C}\right),(\mathrm{d})$ specific humidity $q\left(\mathrm{~g} \mathrm{~kg}^{-1}\right),(\mathrm{e})$ precipitation rate $\left(\mathrm{mm} \mathrm{h}^{-1}\right)$, (f) accumulated precipitation (mm), (g) surface latent heat flux (LHF) and (h) surface sensible heat flux (SHF). Fluxes plots include ERA-Interim. Dashed green lines indicate the approximate launch time of the soundings. Blue shaded area indicates the approximate time of the frontal passage, while gray shaded area indicates the open MCC period. 

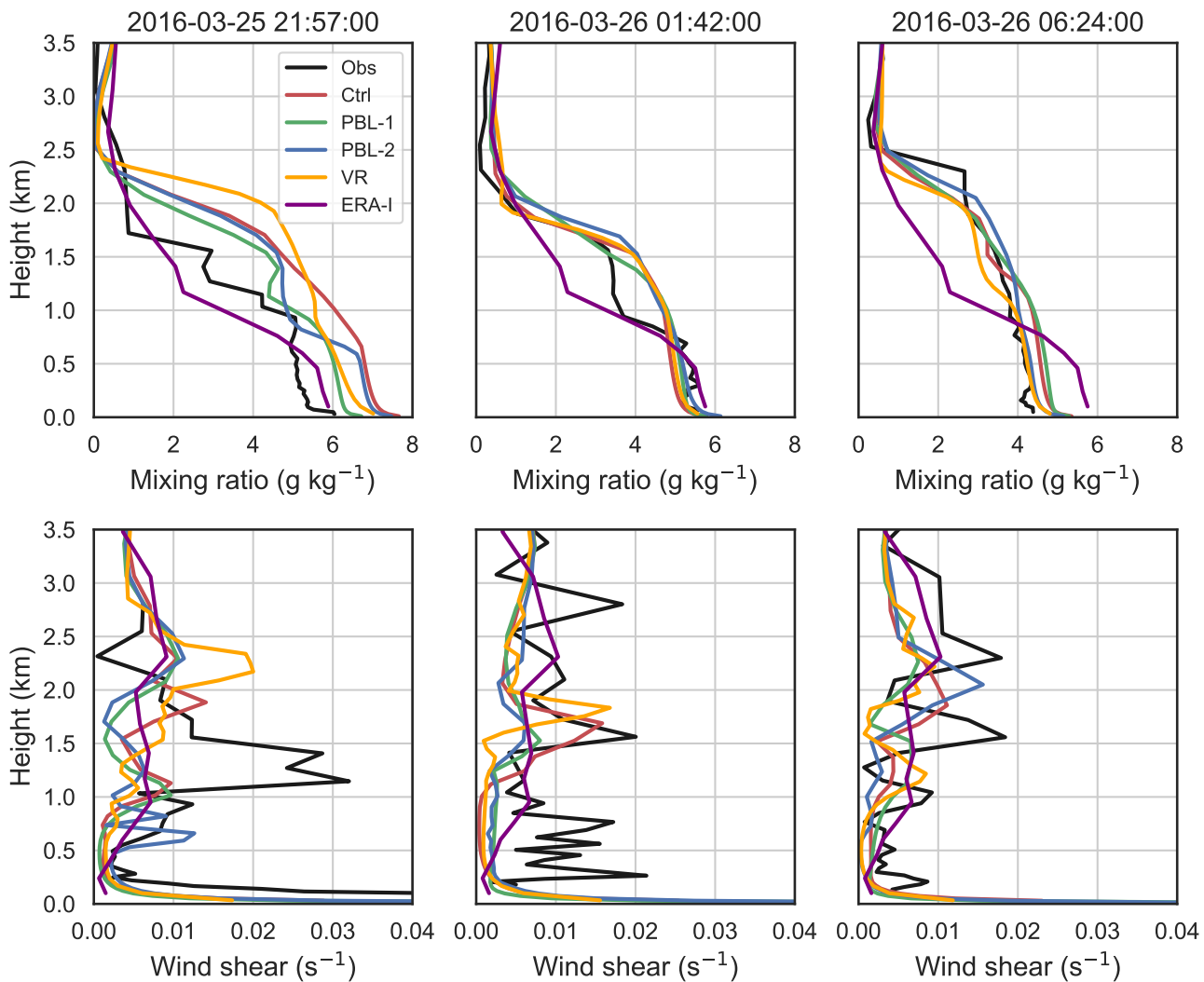

Figure 9. Observed, simulated and ERA-Interim thermodynamic profiles of mixing ratio and wind shear for the Ctrl simulation and the different PBL and VR experiments.

This article is protected by copyright. All rights reserved. 
ulation produces a narrower range of $\mathrm{CTT}$, primarily between -5 and $-15^{\circ} \mathrm{C}$ with an absence of temperatures above freezing. Further, Himawari-8 reveals a west-east gradient of CTT increasing from temperature range -10 to $10^{\circ} \mathrm{C}$ to warmer temperatures in range -5 to $15^{\circ} \mathrm{C}$, which is largely missed in the simulation. Overall, the simulation produces a cloud field that is too homogeneous, featuring some linear patterns and a number of finer-scale open cells. The underrepresentation of ice- or mixed-phase cloud tops is also observed in the histogram of the relative frequencies of the simulated CTP decomposed as a function of simulated temperature (Fig.7b). The histogram shows primarily SLW cloud tops between 0 and $-10^{\circ} \mathrm{C}$. There is also an underestimation of the MCC clouds in the western part of the domain, although a few patches of uniform warm clouds are simulated. For the relative frequency following the ship-track across the duration of the MCC (not shown), virtually all simulated cloud tops are in SLW phase residing in the temperatures range of $0^{\circ} \mathrm{C}$ and $-10^{\circ} \mathrm{C}$, with little evidence of other phases. Differences in the total cloud fraction are also found, with $91 \%$ for Himawari- 8 and $49 \%$ for Ctrl simulation; note that the treatment of partly cloudy pixel in Himawari-8 might overestimate the cloud fraction (Huang et al., 2019).

The corresponding simulated vertical velocities from the two innermost domains $(3 \mathrm{~km}$ and $1 \mathrm{~km})$ are shown in Fig. 10. For both domains, cellular patterns (e.g., rings) of vertical velocity are discernible over an extensive area south of Tasmania, indicating the circulation associated with the cells. Despite the ring-structure being simulated, the horizontal sizes of the cells are much smaller in the simulation than in the satellite image (Fig. 6a,b) . Some regions of the vertical velocity field show unrealistic patterns. For instance, the lack of vertical motion in the southwestern portion of the domain corresponds to the lack of open MCC in the simulation (Fig. 6d).

\subsubsection{Sensitivity Study}

In order to investigate possible reasons for the model deficiencies in simulating the open MCC, MABL characteristics and surface precipitation, a series of numerical simulations are conducted including experiments with different PBL schemes, different and modified MP schemes and vertical spacing (Table 2).

The three PBL schemes tested are able to reproduce areas of open MCC that follow the frontal passage and after the non-precipitating (dry) slot (not shown). The lowlying warm and mixed-phase clouds, however, remain significantly underrepresented. The first two simulated sounding profiles, for PBL-1 and PBL-2 experiments, are less wellmixed, compared to the Ctrl one, but the degree of decoupling is still underestimated (Fig 9). Moreover, all the PBL runs show a wet bias in the lowest $2 \mathrm{~km}$ compared to the observed profiles, particularly in profiles 1 and 3 , which may be a consequence of the warmer SST bias. None of the simulations is able to reproduce the deepening of the MABL height as seen in the observations. Similarly, none of the simulations is able to reproduce the strong shear associated with the decoupling in the PBL.

As discussed earlier, the Ctrl simulation is not able to reproduce mixed cloud-top phase because the SLW is not transforming into ice particles in the simulated environment. The Cooper parameterization to initiate ice in the Thompson scheme is based on a temperature-dependent value of $-20^{\circ} \mathrm{C}$. To force the model to produce more ice at warmer temperatures, as the observations suggest, experiments were performed with this threshold relaxed to warmer temperatures -10 and $0^{\circ} \mathrm{C}$ (MP- 1 and MP-2, respectively). As the temperature of $-10^{\circ} \mathrm{C}$ is attained only in pockets near to the cloud top (Figure 6a), we also tested the threshold of $0^{\circ} \mathrm{C}$ which would be warm enough for ice to nucleate throughout the cloud layer. In addition, in-situ observations suggest a lower $N_{d}$ for maritime clouds over the SO (e.g., Ahn et al., 2017; Huang et al., 2016). Accordingly, a sensitivity experiment using a value of $25 \mathrm{~cm}^{-3}$ (MP-3) is performed with the expectation that the lower $N_{d}$ may facilitate the production of larger droplets. Having larger droplets will in- 
(a)

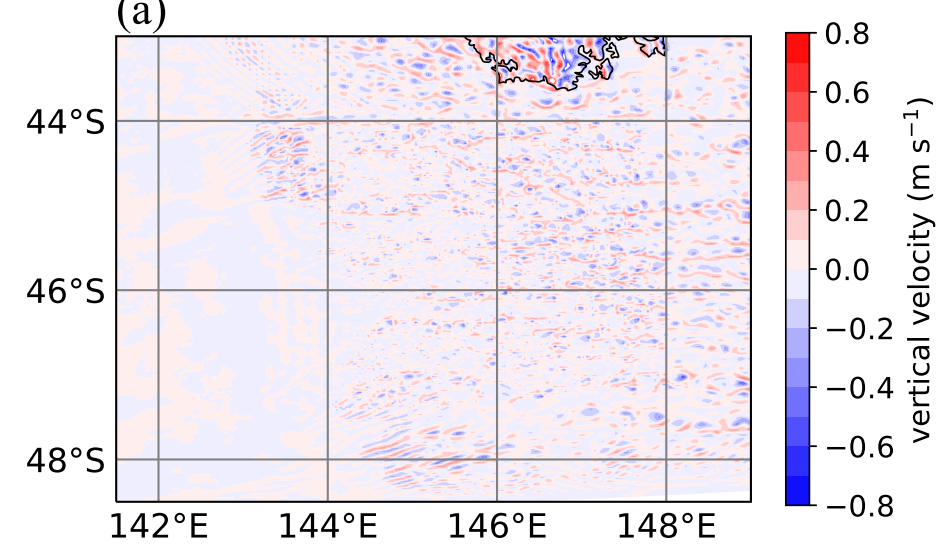

(b)

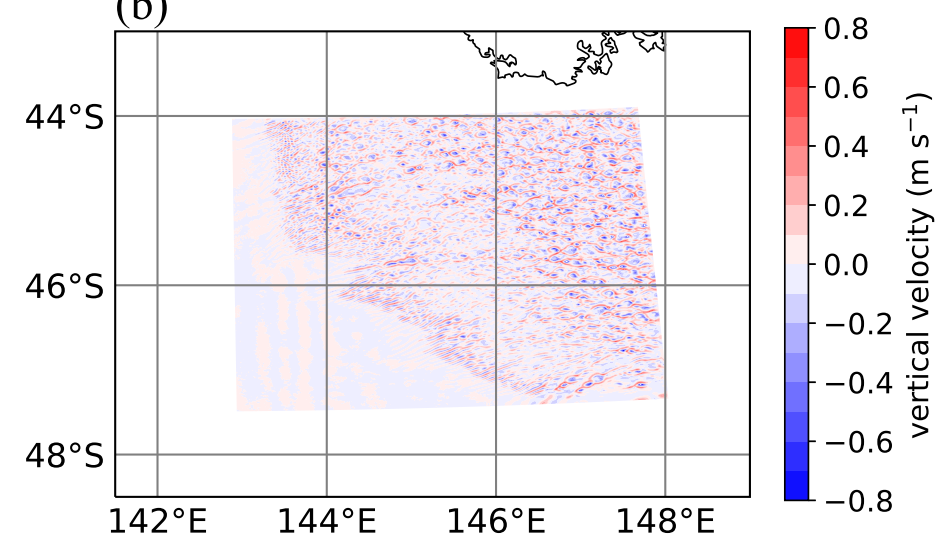

Figure 10. Simulated vertical velocity field at $\sim 250 \mathrm{~m}$ height on 26 March 2016, 10:00 UTC. The horizontal grid spacing of the model is (a) $3 \mathrm{~km}$, domain 3 and (b) $1 \mathrm{~km}$, domain 4 . 
(a)

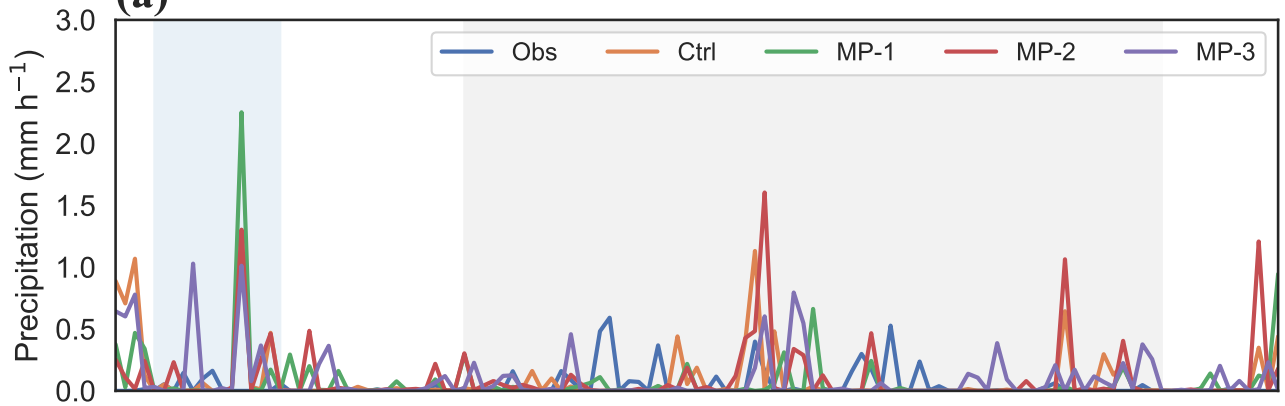

(b)

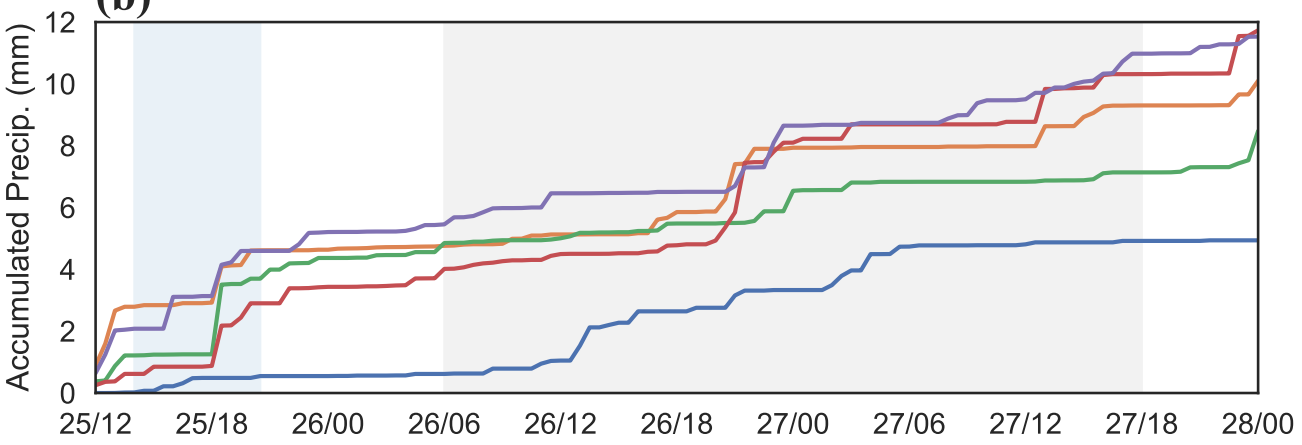

Figure 11. Time series of precipitation for shipborne observations and MP sensitivity experiment simulations, (a) precipitation rate $\left(\mathrm{mm} \mathrm{h}^{-1}\right)$, and (b) accumulated precipitation ( $\mathrm{mm}$ ). Blue shaded area indicates the frontal passages, while gray shaded area indicates the open MCC period. The temporal resolution is $30 \mathrm{~min}$.

crease the rate at which graupel collects liquid water, which can increase the rate of the Hallett-Mossop rime splintering, all else being constant.

Figure 11 shows the time series of the observed precipitation rate and accumulated precipitation with the Ctrl simulation and three MP sensitivity runs. The four simulations reproduce a peak around 1830 UTC on March 25 during frontal passage, most notably in MP-1 $\left(2.25 \mathrm{~mm} \mathrm{~h}^{-1}\right)$ when the primary ice-nucleation temperature is set to $10^{\circ} \mathrm{C}$. During the open MCC period between 1200 UTC on 26 and 0600 UTC on 27 March the accumulated precipitation is better captured by the MP-1 and MP-3 experiments, while the Ctrl and MP-2 experiments largely overestimate the accumulation with a single peak at 2130 UTC on 26 march. While none of the MP simulations are able to substantially improve the total accumulated precipitation amount, it is noted that MP-2 shows more skill in reproducing the accumulated precipitation from the open MCCs compared with the frontal passage and is more consistent with the observations. This suggests that increasing ice production in the model may be important in simulating precipitation in these shallow mixed-phase clouds over the SO.

Changing the ice-nucleation temperature is expected to affect how much mixedphase cloud exists in the simulation. The amount of ice produced by a primary nucleation is expected to be very small due to low cloud condensation nuclei concentrations. After an initial depositional growth, the seeded ice particles could lead to further depletion of water vapor and liquid water content, provided suitable conditions (e.g., vertical velocities) apply. In reality, this is likely to be very rapid for ice embedded in liquid water cloud. The simulation of the initial ice growth is very sensitive to the details of how the deposition-rate and ice-nucleation parameterizations interact. 

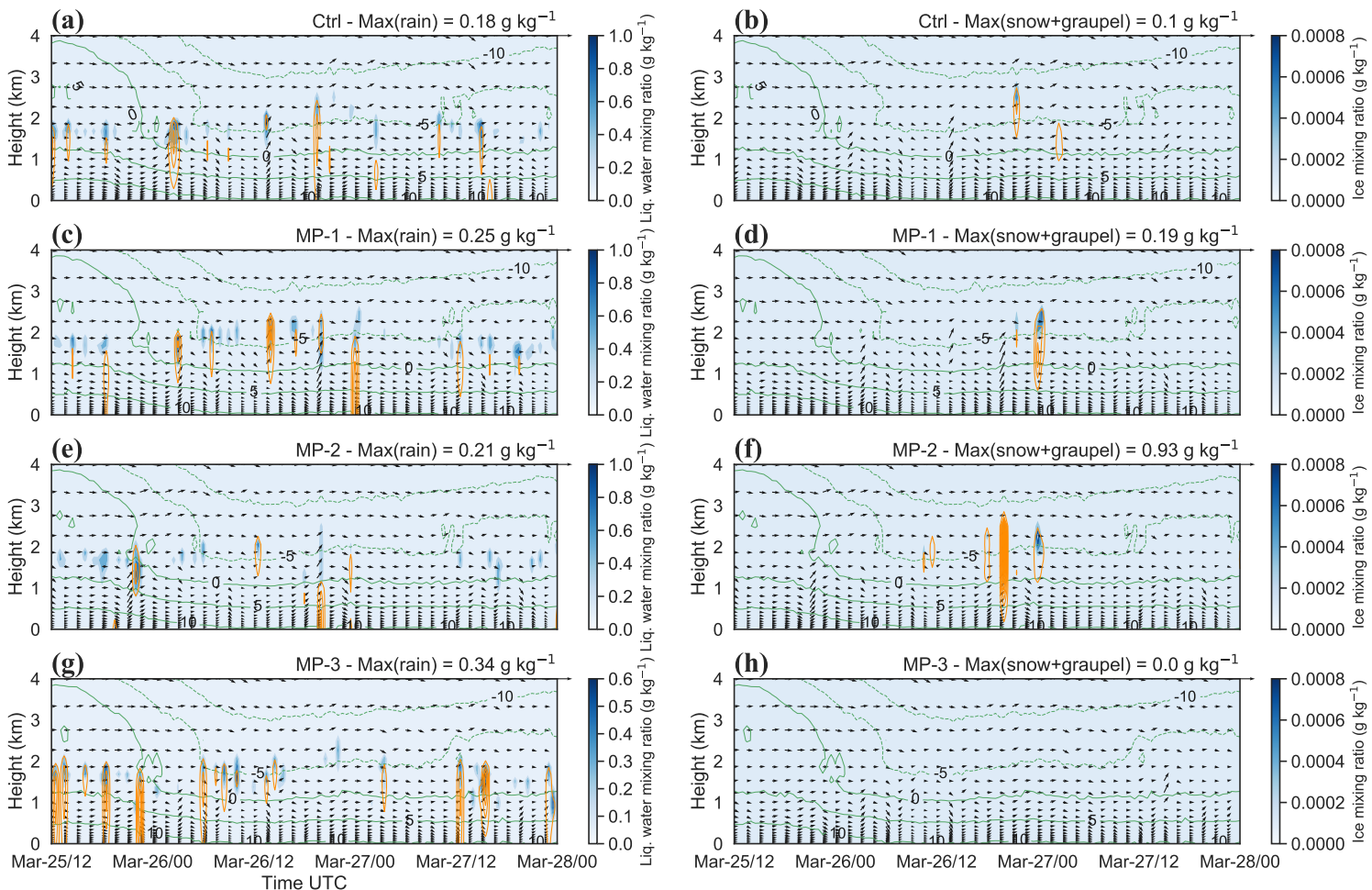

Figure 12. Time series of vertical profiles of the simulated (a) liquid (shaded) with rain (orange lines with $0.8 \mathrm{~g} \mathrm{~kg}^{-1}$ interval) mixing ratios, (b) small ice particles (shaded) with total big ice hydrometeors (orange lines with $0.8 \mathrm{~g} \mathrm{~kg}^{-1}$ interval) for (a-b) Ctrl, (c-d) MP-1, (e-f) MP-2 and (g-h) MP-3 simulations following the ship track, overlayed with the simulated temperatures (green contours) and wind vectors (50 vertical wind $\times \mathrm{N}-\mathrm{S}$ wind). The temporal resolution is 30 $\min$.

Figure 12 shows the time series of vertical profiles of mixing ratios of different hydrometeor species taken from the Ctrl and all the MP runs, following the ship track. All simulations are dominated by liquid phase (cloud liquid + rain) clouds, primarily SLW, between altitudes of 1 and $2.5 \mathrm{~km}$ and at temperatures warmer than $-10^{\circ} \mathrm{C}$. The differences in the simulated solid phases are discernible (right panels) among the four simulations. Not surprisingly, MP-2 produces the largest amount of total ice (ice, snow and graupel). Note the snow and graupel mixing ratios in MP-2 are about one order of magnitude larger than in Ctrl and MP-3. Much larger ice (snow+graupel) mixing ratios in the MP-2 run suggest that riming and aggregation processes are enhanced, leading to higher depletion of SLW. More rain is produced for all the sensitivity experiments in comparison to Ctrl, which is not a surprise given that the intent of the changes is to enhance ice production within the mixed-phase clouds. One exception is MP-3, which produces the greatest amount of precipitation with a maximum rain water mixing ratio of 0.34 $\mathrm{g} \mathrm{kg}^{-1}$. The increased precipitation in MP-3 is due, primarily, to efficient warm rain processes resulting from the increased droplet size (Fig. 12g), rather than ice multiplication at sub-freezing temperatures via Hallett-Mossop processes (Fig. 12h).

As discussed before, the Ctrl simulation is unable to reproduce the evolution of the MABL height and it simulates an MABL that is too well mixed compared to the observations. One of the possible reasons may be that the vertical resolution in the Ctrl simulation is not sufficient to resolve the MABL structure and associated turbulent processes. 
To examine the role of vertical resolution, a simulation with increased vertical levels throughout the cloud layer is also undertaken (VR experiment). This modified $64 \eta$-level spacing uses a homogenous spacing with $8 \mathrm{hPa}$ interval from the surface (1013 hPa) up to the level of cloud top at $\sim 750 \mathrm{hPa}(\sim 2.5 \mathrm{~km})$, allowing $33 \eta$-levels within the MABL. Figure 9 also shows the thermodynamic profiles of the three simulated profiles for the VR experiment. The most significant differences are in the first profile, where the VR simulation produces a main inversion higher than the Ctrl simulation and much higher than the observed profile, with a strong wind shear on the cloud top. The VR simulation also differs in the moisture content compared to the Ctrl simulation, featuring a drier MABL and less surface precipitation (not shown). Further, the simulated wind shear does not reproduce changes of winds across the vertical profiles and the decoupling of the cloud layer is not captured.

\section{Discussion and Conclusions}

Shipborne and Himawari-8 satellite observations are used to characterize the properties of cloud fields and marine atmospheric boundary layer (MABL) thermodynamic structure during a sustained period of open mesoscale cellular convection (MCC) on 2527 March 2016 during the CAPRICORN field experiment over the Southern Ocean (SO). The observations reveal a widespread shallow convective cloud field spanning thousands of square kilometers in the post-frontal sector, with the common presence of supercooledliquid and mixed-phase at cloud-top temperatures down to $\sim-9^{\circ} \mathrm{C}$. The majority of these open MCC clouds were located near the base of the main inversion and observed to be intermittently precipitating.

During a brief non-precipitating period after the frontal passage, a transition layer is detected by three soundings. After the cloud-free slot the ship passed an extensive field of open MCC, with signs of ice-phase precipitation at cloud base and an enhanced intensity of surface precipitation. While ground-based radar-lidar retrievals suffer from inherent uncertainties and limitations, both phase classifications found evidence of ice in these clouds. Consistent with these observations, the merged A-Train product raDAR/liDARMASK (DARDAR-MASK, Delanoë \& Hogan, 2010; Huang et al., 2012) from a nearby overpass also shows the presence of ice in this is shallow cloud field (Fig. S4 in supporting information). The presence of ice-phase precipitation in shallow open MCC clouds is consistent with an earlier study (Huang et al., 2017), where evidence of secondary ice formation (likely via the Hallett-Mossop mechanism) was found in the open MCC over the SO using aircraft observations. While ice multiplication is not the only factor that influences the precipitation efficiency, this process may be an important step in the development of precipitation within open MCC over the SO. The mixed-phase precipitation may further affect the boundary dynamics as it is observed to melt below cloud base, which provides immediate cooling to the downdraft in addition to any evaporative cooling. The thermodynamic effects of this freezing/melting of precipitation potentially offers a major point of difference between SO open MCC and the pockets of open cells observed over the southeast Pacific (Stevens et al., 2005); the secondary ice production in-cloud and melting below cloud introduces a unique decoupling mechanism to this environment. Coinciding with the open MCC clouds, surface temperature showed evidence of cold pool formation in the wake of precipitation. These cold pools were evident for approximately 1 to 2 hours in duration, and they commonly decreased the observed surface air temperature by 1 to 2 degrees, similar to observations of cold pools in the wake of trade cumulus precipitation (Zuidema et al., 2012). Eddy-permitting simulations using prescribed surface heat fluxes by Zhou et al. (2018) found that MCC cloud morphology was more strongly influenced by moisture stratification than moist cold pools. They also found that interactive fluxes had no qualitative impact on their results. This is in contrast to this case study where the observed heat fluxes directly responded to the cold pools. We note that previous studies have suggested that for open MCC formation and organization, evap- 
orative cooling from precipitation is a fundamental driving process (Savic-Jovcic \& Stevens, 2008; H. Wang \& Feingold, 2009a). We further note that the simulations of Zhou et al. (2018) were based on field observations of pockets of open cells from the VOCALS-Rex field campaign (Wood et al., 2011). These pockets of open cells were observed over warmer waters at lower latitudes with no evidence of ice being present.

The mid-latitude $\mathrm{SO}$ is a region characterized by a high density of extra-tropical cyclones and fronts (e.g., Hoskins \& Hodges, 2005; Simmonds \& Keay, 2000). Many studies have attributed a large percentage of precipitation to cold-front passages. For instance, Catto et al. (2012) employed the Global Precipitation Climatology Project (GPCP), attributing most (70-90\%) of the precipitation to frontal systems in this region. Z. Wang et al. (2015), employing the surface observations at Macquarie Island $\left(54.62^{\circ} \mathrm{S}, 158.85^{\circ} \mathrm{E}\right)$, estimated the fraction to be $\sim 60 \%$. In our case study, surface precipitation generated by the open MCC clouds in the post-frontal air mass was observed to have notably higher rates compared to the frontal precipitation. This finding is consistent with the climatology presented in Lang et al. (2018), who used long-term surface precipitation observations from Macquarie Island to find that the ERA-Interim reanalysis systematically underestimates precipitation not directly associated with cold fronts by $11 \%$. These results further highlight that precipitation from shallow convection may play an important role in the precipitation budget over the SO.

After the open MCC clouds the ship passed into a cloud field with a larger cloud coverage composed of closed MCC. During a transition period between these two cloud morphologies on 27 March, the precipitation was considerably lower and remained minimal during the closed MCC period. The air-sea temperature difference increased due to warmer sea surface temperatures (SST), coinciding with a decrease in the air temperature, which led to a stronger net surface heat flux, remaining during the closed MCC period. Over the subtropics cloud-topped boundary layer, a link between warming SST and increases in the surface latent heat flux (LHF) is a driving mechanism of decoupling by enhancing buoyancy in the cloud layer faster than in the subcloud layer (e.g., Bretherton \& Wyant, 1997), which suggests that during the closed MCC period the LHF might be generating a systematic decoupling. However, there was no sounding launch during this period to test this hypothesis. The observations were used to evaluate a series of highresolution WRF simulations, including a series of experiments with modified physical parameterization schemes and model vertical resolution. Although the control (Ctrl) simulation demonstrated a level of skill in representing surface meteorological variables, the simulations are found to have difficulties in producing post-frontal open MCC cloud fields, mixed-phase cloud tops, and surface precipitation. Shipborne and Himawari-8 satellite observations showed an extensive field of open MCC clouds in the range of temperatures between -10 and $10^{\circ} \mathrm{C}$, yet the simulations have difficulties in producing the observed morphology and microphysical characteristics. Further, a warm bias of $\sim 4^{\circ} \mathrm{C}$ is identified in the ERA-Interim SST during the open MCC period, which may explain the overestimation of surface fluxes in the simulations.

The simulations (Ctrl and sensitivity experiments) showed a more well mixed MABL, underestimating the degree of decoupling. The underrepresentation of decoupling may be linked to the underrepresentation of cold pools as a result of suppressed evaporative cooling. The latter is consistent with the overestimation of the humidity within the MABL, which corresponds to the underestimate of wind shear strength in the simulations. Further, none of the PBL schemes (YSU, ACM2 and MYJ) is able to reproduce the deepening of the MABL height as seen in the sounding observations. Stronger surface heat fluxes and the corresponding stronger mixing within the MABL may be also linked to this bias in the decoupling.

The simulation with the Thompson scheme underpredicted the frozen hydrometeors at sub-freezing temperatures while producing large quantities of supercooled liquid clouds. In the MP sensitivity experiments, we forced the Thompson scheme to be 
more active at removing SLW from the stratiform cloud by initializing ice production at warmer temperatures $\left(-10\right.$ and $0^{\circ} \mathrm{C}, \mathrm{MP}-1$ and MP-2, respectively). These adjustments in the Thompson scheme led to a higher production of ice compared to the Ctrl run, which represents a limited success of the MP sensitivity experiments. The underprediction of ice in the mixed-phase open MCC clouds persisted with a reduced $N_{d}$, where the model simulated bigger droplets with the expectation of triggering the Hallett-Mossop ice multiplication process. All MP sensitivity experiments produced more rain in comparison to Ctrl. This is not a surprise given that the experiments were designed to enhance ice production within the mixed-phase clouds, which would consequently favor rain production. Overall, the sensitivity experiments highlight the importance of ice processes (likely secondary ice processes) in precipitation production in the open MCC clouds over the SO, consistent with in-situ evidence (Huang et al., 2017).

Despite being a single case study, this represents a unique set of observations to study mixed-phase open MCCs, which are a common feature over the mid-latitude SO, particularly under cold air advection (McCoy et al., 2017). Our analysis emphasizes the role of ice processes at sub-freezing temperatures in the development of precipitation in these clouds and their potential role in decoupling the boundary layer through downdrafts and cold pools. As the model simulations showed, the frontal precipitation intensity is overestimated while the precipitation frequency of the open MCC clouds is underestimated. This further suggests that some available precipitation products, such as reanalysis products (e.g., Lang et al., 2018) and satellite products (e.g., Behrangi et al., 2014), may under-represent the frequency and intensity of precipitation generated by shallow convection over the SO that is not immediately associated with fronts. This might be partly because current precipitation products are not able to capture the low-level cloud structure correctly, which might underestimate precipitation over the SO. An exhaustive evaluation of precipitation reanalysis products and NWP model, plus the identification of the key meteorological, dynamical and microphysical processes involved in the generation of precipitation using the recent international field experiments conducted over the $\mathrm{SO}$ would provide a better understanding of precipitation in shallow convection and the associated biases.

\section{Acknowledgments}

This work is supported by Australian Research Council Discovery Projects DP190101362. The Bureau of Meteorology's contribution to this study was partly funded by the National Environmental Science Program (NESP), Australia, and the Australian Antarctic Program Partnership (AAPP). The authors wish to thank the CSIRO Marine National Facility for its grant of sea time on Investigator and associated personnel, scientific equipment, and data management. The CAPRICORN-2016 data are publicly available from the CSIRO Data Access Portal as part of the Research Voyage: IN2016-V02 (https://doi.org/10.25919/5f688fcc97166).

\section{References}

Abel, S. J., Boutle, I. A., Waite, K., Fox, S., Brown, P. R., Cotton, R., ... Bower, K. N. (2017). The role of precipitation in controlling the transition from stratocumulus to cumulus clouds in a Northern Hemisphere cold-air outbreak. Journal of the Atmospheric Sciences, 74 (7), 2293-2314. doi: https://doi.org/10.1175/JAS-D-16-0362.1

Ahn, E., Huang, Y., Chubb, T. H., Baumgardner, D., Isaac, P., de Hoog, M., ... Manton, M. J. (2017). In situ observations of wintertime low-altitude clouds over the Southern Ocean. Quarterly Journal of the Royal Meteorological Society, 143(704), 1381-1394. doi: https://doi.org/10.1002/qj.3011

Alexander, S., \& Protat, A. (2018). Cloud properties observed from the surface and by satellite at the northern edge of the southern ocean. Journal of Geophys- 

2017JD026552

Atkinson, B. W., \& Zhang, J. W. (1996). Mesoscale shallow convection in the atmosphere. Reviews of Geophysics, 34(4), 403-431. doi: https://doi.org/10.1029/ 96RG02623

Behrangi, A., Lebsock, M., Wong, S., \& Lambrigtsen, B. (2012). On the quantification of oceanic rainfall using spaceborne sensors. Journal of Geophysical Research: Atmospheres, 117(D20). doi: https://doi.org/10.1029/2012JD017979

Behrangi, A., Stephens, G., Adler, R. F., Huffman, G. J., Lambrigtsen, B., \& Lebsock, M. (2014). An update on the oceanic precipitation rate and its zonal distribution in light of advanced observations from space. Journal of Climate, 27(11), 3957-3965. doi: https://doi.org/10.1175/JCLI-D-13-00679.1

Bennartz, R. (2007). Global assessment of marine boundary layer cloud droplet number concentration from satellite. Journal of Geophysical Research: Atmospheres, 112(D2). doi: https://doi.org/10.1029/2006JD007547

Bharti, V., Schulz, E., Fairall, C. W., Blomquist, B. W., Huang, Y., Protat, A., ... Manton, M. J. (2019). Assessing surface heat flux products with in situ observations over the australian sector of the southern ocean. Journal of Atmospheric and Oceanic Technology, 36(9), 1849-1861. doi: https://doi.org/10.1175/JTECH-D-19-0009.1

Boers, R. (1995). Influence of seasonal variation in cloud condensation nuclei, drizzle, and solar radiation, on marine stratocumulus optical depth. Tellus B: Chemical and Physical Meteorology, 47(5), 578-586. doi: https://doi.org/ 10.3402/tellusb.v47i5.16073

Boers, R., Jensen, J. B., \& Krummel, P. B. (1998). Microphysical and short-wave radiative structure of stratocumulus clouds over the Southern Ocean: Summer results and seasonal differences. Quarterly Journal of the Royal Meteorological Society, 124(545), 151-168. doi: https://doi.org/10.1002/qj.49712454507

Bretherton, C. S., \& Wyant, M. C. (1997). Moisture transport, lower-tropospheric stability, and decoupling of cloud-topped boundary layers. Journal of the Atmospheric Sciences, 54(1), 148-167. doi: https://doi.org/10.1175/ 1520-0469(1997)054<0148:MTLTSA $\rangle 2.0 . C O ; 2$

Catto, J. L., Jakob, C., Berry, G., \& Nicholls, N. (2012). Relating global precipitation to atmospheric fronts. Geophysical Research Letters, 39(10). doi: https:// doi.org/10.1029/2012GL051736

Chen, F., \& Dudhia, J. (2001). Coupling an advanced land surface-hydrology model with the penn state-ncar mm5 modeling system. part i: Model implementation and sensitivity. Monthly Weather Review, 129(4), 569-585. doi: https://doi.org/10.1175/1520-0493(2001)129,0569:CAALSH.2.0.CO;2

Comstock, K. K., Wood, R., Yuter, S. E., \& Bretherton, C. S. ～(2004). Reflectivity and rain rate in and below drizzling stratocumulus. Quarterly Journal of the Royal Meteorological Society: A journal of the atmospheric sciences, applied meteorology and physical oceanography, 130(603), 2891-2918. doi: https://doi.org/10.1256/qj.03.187

Comstock, K. K., Yuter, S. E., Wood, R., \& Bretherton, C. S. $\quad$ (2007). The three-dimensional structure and kinematics of drizzling stratocumulus. Monthly Weather Review, 135(11), 3767-3784. doi: https://doi.org/10.1175/ 2007MWR1944.1

Cooper, W. A. (1986). Ice initiation in natural clouds. In Precipitation enhancement-a scientific challenge (pp. 29-32). Springer.

Dee, D. P., Uppala, S. M., Simmons, A. J., Berrisford, P., Poli, P., Kobayashi, S., .. . Others (2011). The ERA-Interim reanalysis: Configuration and performance of the data assimilation system. Quarterly Journal of the Royal Meteorological Society, 137(656), 553-597. doi: https://doi.org/10.1002/qj.828

Delanoë, J., \& Hogan, R. J. (2010). Combined cloudsat-calipso-modis retrievals 
of the properties of ice clouds. Journal of Geophysical Research: Atmospheres, 115(D4). doi: https://doi.org/10.1029/2009JD012346

Delanoë, J., Protat, A., Vinson, J.-P., Brett, W., Caudoux, C., Bertrand, F., ... others (2016). BASTA: A 95-GHz FMCW Doppler radar for cloud and fog studies. Journal of Atmospheric and Oceanic Technology, 33(5), 1023-1038. doi: https://doi.org/10.1175/JTECH-D-15-0104.1

Fairall, C., White, A., Edson, J., \& Hare, J. ～(1997). Integrated shipboard measurements of the marine boundary layer. Journal of Atmospheric and Oceanic Technology, 14 (3), 338-359. doi: https://doi.org/10.1175/ 1520-0426(1997)014〈0338:ISMOTM $\rangle 2.0 . \mathrm{CO} ; 2$

Field, P. R., Cotton, R. J., Mcbeath, K., Lock, A. P., Webster, S., \& Allan, R. P. (2014). Improving a convection-permitting model simulation of a cold air outbreak. Quarterly Journal of the Royal Meteorological Society, 140(678), 124-138. doi: https://doi.org/10.1002/qj.2116

Field, P. R., \& Wood, R. (2007). Precipitation and cloud structure in midlatitude cyclones. Journal of Climate, 20(2), 233-254. doi: https://doi.org/10.1175/ JCLI3998.1

Hande, L. B., Siems, S. T., Manton, M. J., \& Belusic, D. (2012). Observations of wind shear over the Southern Ocean. Journal of Geophysical Research: Atmospheres, 117(D12). doi: https://doi.org/10.1029/2012JD017488

Haynes, J. M., Marchand, R. T., Luo, Z., Bodas-Salcedo, A., \& Stephens, G. L. (2007). A multipurpose radar simulation package: Quickbeam. Bulletin of the American Meteorological Society, 88(11), 1723-1728. doi: https://doi.org/10.1175/BAMS-88-11-1723

Heidinger, A. (2011). NOAA NESDIS Center for Satellite Applications and Research algorithm theoretical basis document: ABI cloud mask. Version, 2.

Hong, S., Noh, Y., \& Dudhia, J. (2006). A new vertical diffusion package with an explicit treatment of entrainment processes. Monthly Weather Review, 134(9), 2318-2341. doi: https://doi.org/10.1175/MWR3199.1

Hoskins, B. J., \& Hodges, K. I. (2005). A new perspective on southern hemisphere storm tracks. Journal of Climate, 18(20), 4108-4129. doi: https://doi.org/10 $.1175 /$ JCLI3570.1

Hu, Y., Rodier, S., Xu, K.-m., Sun, W., Huang, J., Lin, B., ... Josset, D. (2010). Occurrence, liquid water content, and fraction of supercooled water clouds from combined CALIOP/IIR/MODIS measurements. Journal of Geophysical Research: Atmospheres, 115(D4). doi: https://10.1029/2009JD012384

Huang, Y., Chubb, T., Baumgardner, D., deHoog, M., Siems, S. T., \& Manton, M. J. (2017). Evidence for secondary ice production in Southern Ocean open cellular convection. Quarterly Journal of the Royal Meteorological Society, 143(704), 1685-1703. doi: https://doi.org/10.1002/qj.3041

Huang, Y., Franklin, C. N., Siems, S. T., Manton, M. J., Chubb, T., Lock, A., ... Klekociuk, A. (2015). Evaluation of boundary-layer cloud forecasts over the Southern Ocean in a limited-area numerical weather prediction system usingin situ, space-borne and ground-based observations. Quarterly Journal of the Royal Meteorological Society, 141(691), 2259-2276. doi: https://doi.org/10.1002/qj.2519

Huang, Y., Protat, A., Siems, S. T., \& Manton, M. J. (2015). A-Train observations of maritime midlatitude storm-track cloud systems: Comparing the Southern Ocean against the North Atlantic. Journal of Climate, 28(5), 1920-1939. doi: https://doi.org/10.1175/JCLI-D-14-00169.1

Huang, Y., Siems, S., Manton, M., Protat, A., Majewski, L., \& Nguyen, H. (2019). Evaluating Himawari-8 Cloud Products Using Shipborne and CALIPSO Observations: Cloud-top Height and Cloud-top Temperature. Journal of Atmospheric and Oceanic Technology, 36(12), 2327-2347. doi: https://doi.org/10.1175/JTECH-D-18-0231.1 
Huang, Y., Siems, S. T., Manton, M. J., Protat, A., \& Delanoë, J. (2012). A study on the low-altitude clouds over the Southern Ocean using the DARDARMASK. Journal of Geophysical Research: Atmospheres, 117(D18). doi: https://doi.org/10.1029/2012JD017800

Huang, Y., Siems, S. T., Manton, M. J., Rosenfeld, D., Marchand, R., McFarquhar, G. M., \& Protat, A. (2016). What is the role of sea surface temperature in modulating cloud and precipitation properties over the Southern Ocean? Journal of Climate, 29(20), 7453-7476. doi: https://doi.org/10.1175/ JCLI-D-15-0768.1

Huang, Y., Siems, S. T., Manton, M. J., \& Thompson, G. (2014). An evaluation of WRF simulations of clouds over the Southern Ocean with ATrain observations. Monthly Weather Review, 142(2), 647-667. doi: https://doi.org/10.1175/MWR-D-13-00128.1

Iacono, M. J., Delamere, J. S., Mlawer, E. J., Shephard, M. W., Clough, S. A., \& Collins, W. D. (2008). Radiative forcing by long-lived greenhouse gases: Calculations with the aer radiative transfer models. Journal of Geophysical Research: Atmospheres, 113(D13). doi: https://doi.org/10.1029/2008JD009944

Jensen, J. B., Lee, S., Krummel, P. B., Katzfey, J., \& Gogoasa, D. (2000). Precipitation in marine cumulus and stratocumulus. Atmospheric Research, 54(2-3), 117-155. Retrieved from http://linkinghub.elsevier.com/retrieve/pii/ S0169809500000405 doi: https://doi.org/10.1016/S0169-8095(00)00040-5

Jones, C. R., Bretherton, C. S., \& Leon, D. (2011). Coupled vs. decoupled boundary layers in vocals-rex. Atmospheric Chemistry and Physics, 11(14), 7143-7153. doi: https://doi.org/0.5194/acp-11-7143-2011

Klepp, C. (2015). The oceanic shipboard precipitation measurement network for surface validationoceanrain. Atmospheric Research, 163, 74-90. doi: https://doi .org/10.1175/JTECH-D-15-0104.1

Lang, F., Huang, Y., Siems, S., \& Manton, M. (2018). Characteristics of the Marine Atmospheric Boundary Layer Over the Southern Ocean in Response to the Synoptic Forcing. Journal of Geophysical Research: Atmospheres, 123(15). doi: https://doi.org/10.1029/2018JD028700

Lang, F., Huang, Y., Siems, S. T., \& Manton, M. J. (2020). Evidence of a diurnal cycle in precipitation over the Southern Ocean as observed at Macquarie Island. Atmosphere, 11(2), 181. doi: https://doi.org/10.3390/atmos11020181

Mace, G. G., \& Protat, A. (2018a). Clouds over the Southern Ocean as observed from the R/V investigator during CAPRICORN. Part I: Cloud occurrence and phase partitioning. Journal of Applied Meteorology and Climatology, 57(8), 1783-1803. doi: https://doi.org/10.1175/JAMC-D-17-0194.1

Mace, G. G., \& Protat, A. (2018b). Clouds over the Southern Ocean as observed from the R/V investigator during CAPRICORN. Part II: The properties of nonprecipitating stratocumulus. Journal of Applied Meteorology and Climatology, 57(8), 1805-1823. doi: https://doi.org/10.1175/JAMC-D-17-0195.1

McCoy, I. L., Wood, R., \& Fletcher, J. K. (2017). Identifying Meteorological Controls on Open and Closed Mesoscale Cellular Convection Associated with Marine Cold Air Outbreaks. Journal of Geophysical Research: Atmospheres, 122(21), 11,678-11,702. doi: https://doi.org/10.1002/2017JD027031

McFarquhar, G. M., Bretherton, C., Marchand, R., Protat, A., DeMott, P. J., Alexander, S. P., ... others (2020). Observations of clouds, aerosols, precipitation, and surface radiation over the southern ocean: An overview of capricorn, marcus, micre and socrates. Bulletin of the American Meteorological Society, 1-92. doi: https://doi.org/10.1175/BAMS-D-20-0132.1

Mellor, G. L., \& Yamada, T. (1982). Development of a turbulence closure model for geophysical fluid problems. Reviews of Geophysics, 20(4), 851-875. doi: https://doi.org/10.1029/RG020i004p00851

Mlawer, E. J., Taubman, S. J., Brown, P. D., Iacono, M. J., \& Clough, S. A. 
(1997). Radiative transfer for inhomogeneous atmospheres: Rrtm, a validated correlated-k model for the longwave. Journal of Geophysical Research: Atmospheres, 102(D14), 16663-16682. doi: https://doi.org/10.1029/97JD00237

Morrison, A. E., Siems, S. T., Manton, M. J., \& Nazarov, A. (2010). A modeling case study of mixed-phase clouds over the Southern Ocean and Tasmania. Monthly Weather Review, 138(3), 839-862. doi: https://doi.org/10.1175/ 2009MWR3011.1

Muhlbauer, A., McCoy, I. L., \& Wood, R. (2014). Climatology of stratocumulus cloud morphologies: microphysical properties and radiative effects. Atmospheric Chemistry and Physics, 14(13), 6695-6716. doi: https://doi.org/ 10.5194/acpd-14-6981-2014

Noh, Y.-J., Miller, S. D., Heidinger, A. K., Mace, G. G., Protat, A., \& Alexander, S. P. (2019). Satellite-based detection of daytime supercooled liquid-topped mixed-phase clouds over the southern ocean using the advanced himawari imager. Journal of Geophysical Research: Atmospheres, 124(5), 2677-2701. doi: https://10.1029/2018JD029524

Pan, H., \& Wu, W. (1995). Implementing a mass flux convection parameterization package for the nmc medium-range forecast model. $\quad$ Office Note 409, NOAA/EMC.

Pavolonis, M. (2010). GOES-R Advanced Baseline Imager (ABI) algorithm theoretical basis document for cloud type and cloud phase, version 2.0. NOAA NESDIS Center for Satellite Applications and Research Algorithm Theoretical Basis Doc.

Pleim, J. E. (2007). A combined local and nonlocal closure model for the atmospheric boundary layer. part i: Model description and testing. Journal of Applied Meteorology and Climatology, 46(9), 1383-1395. doi: https://doi.org/10 $.1175 / \mathrm{JAM} 2539.1$

Reisner, J., Rasmussen, R., \& Bruintjes, R. (1998). $\quad$ Explicit forecasting of supercooled liquid water in winter storms using the mm5 mesoscale model. Quarterly Journal of the Royal Meteorological Society, 124(548), 1071-1107. doi: https://doi.org/10.1002/qj.49712454804

Royer, P., Bizard, A., Sauvage, L., \& Thobois, L. (2014). Validation protocol and intercomparison campaigns with the r-man510 aerosol lidar. In Proc. 17th int. symp. for the advancement of boundary-layer remote sensing.

Sandu, I., \& Stevens, B. (2011). On the factors modulating the stratocumulus to cumulus transitions. Journal of Atmospheric Sciences, 68(9), 1865-1881. doi: https://doi.org/10.1175/2011JAS3614.1

Savic-Jovcic, V., \& Stevens, B. (2008). The structure and mesoscale organization of precipitating stratocumulus. Journal of the Atmospheric Sciences, 65(5), 1587-1605. doi: https://doi.org/10.1175/2007JAS2456.1

Sharon, T. M., Albrecht, B. A., Jonsson, H. H., Minnis, P., Khaiyer, M. M., van Reken, T. M., .. Flagan, R. (2006). Aerosol and cloud microphysical characteristics of rifts and gradients in maritime stratocumulus clouds. Journal of the Atmospheric Sciences, 63(3), 983-997. doi: https://doi.org/10.1175/ JAS3667.1

Simmonds, I., \& Keay, K. (2000). Mean Southern Hemisphere extratropical cyclone behavior in the 40-year NCEP-NCAR reanalysis. Journal of Climate, 13(5), 873-885. doi: https://doi.org/10.1175/1520-0442(2000)013<0873:MSHECB $\rangle 2.0$ $\mathrm{CO} ; 2$

Skamarock, W. C., Klemp, J. B., Dudhia, J., Gill, D. O., Barker, D. M., Duda, M. G., ... Powers, J. P. (2008). A description of the advanced research wrf version 3. NCAR/TN-4751STR NCAR Tech. Note.

Stevens, B., Vali, G., Comstock, K., Wood, R., Van Zanten, M. C., Austin, P. H., ... Lenschow, D. H. (2005). Pockets of open cells and drizzle in marine stratocumulus. Bulletin of the American Meteorological Society, 86(1), 51-58. doi: 
https://doi.org/10.1175/BAMS-86-1-51

Tan, I., \& Storelvmo, T. (2016). Sensitivity study on the influence of cloud microphysical parameters on mixed-phase cloud thermodynamic phase partitioning in cam5. Journal of the Atmospheric Sciences, 73(2), 709-728. doi: https://10.1175/JAS-D-15-0152.1

Terai, C. R., Bretherton, C. S., Wood, R., \& Painter, G. (2014). Aircraft observations of aerosol, cloud, precipitation, and boundary layer properties in pockets of open cells over the southeast Pacific. Atmospheric Chemistry and Physics, 14 (15), 8071-8088. doi: https://doi.org/10.5194/acp-14-8071-2014

Thompson, G., Field, P. R., Rasmussen, R. M., \& Hall, W. D. (2008). Explicit forecasts of winter precipitation using an improved bulk microphysics scheme. part ii: Implementation of a new snow parameterization. Monthly Weather Review, 136(12), 5095-5115. doi: https://doi.org/10.1175/2008MWR2387.1

Tomassini, L., Field, P. R., Honnert, R., Malardel, S., McTaggart-Cowan, R., Saitou, K., ... Seifert, A. (2017). The g rey z one cold air outbreak global model intercomparison: A cross evaluation using large-eddy simulations. Journal of Advances in Modeling Earth Systems, 9(1), 39-64. doi: https://doi.org/10.1002/2016MS000822

Trenberth, K. E., \& Fasullo, J. T. (2010). Simulation of present-day and twentyfirst-century energy budgets of the southern oceans. Journal of Climate, 23(2), 440-454. doi: https://doi.org/10.1175/2009JCLI3152.1

Vincent, C. L., Hahmann, A. N., \& Kelly, M. C. (2012). Idealized Mesoscale Model Simulations of Open Cellular Convection Over the Sea. Boundary-Layer Meteorology, 142 (1), 103-121. doi: https://doi.org/10.1007/s10546-011-9664-7

Wang, H., \& Feingold, G. (2009a). Modeling mesoscale cellular structures and drizzle in marine stratocumulus. Part I: Impact of drizzle on the formation and evolution of open cells. Journal of the Atmospheric Sciences, 66(11), 3237-3256. doi: https://doi.org/10.1175/2009JAS3022.1

Wang, H., \& Feingold, G. (2009b). Modeling mesoscale cellular structures and drizzle in marine stratocumulus. Part II: The microphysics and dynamics of the boundary region between open and closed cells. Journal of the Atmospheric Sciences, 66 (11), 3257-3275. doi: 10.1175/2009JAS3120.1

Wang, Y., McFarquhar, G. M., Rauber, R. M., Zhao, C., Wu, W., Finlon, J. A., ... others (2020). Microphysical properties of generating cells over the southern ocean: Results from socrates. Journal of Geophysical Research: Atmospheres, 125(13), e2019JD032237. doi: https://doi.org/10.1029/2019JD032237

Wang, Z., Belusic, D., Huang, Y., Siems, S. T., \& Manton, M. J. (2016). Understanding orographic effects on surface observations at Macquarie Island. Journal of Applied Meteorology and Climatology, 55(11), 2377-2395. doi: https:// doi.org/10.1175/JAMC-D-15-0305.1

Wang, Z., Siems, S. T., Belusic, D., Manton, M. J., \& Huang, Y. (2015). A climatology of the precipitation over the Southern Ocean as observed at Macquarie Island. Journal of Applied Meteorology and Climatology, 54 (12), 2321-2337. doi: https://doi.org/10.1175/JAMC-D-14-0211.1

Williams, K. D., Bodas-Salcedo, A., Déqué, M., Fermepin, S., Medeiros, B., Watanabe, M., ... Williamson, D. L. (2013). The Transpose-AMIP II experiment and its application to the understanding of Southern Ocean cloud biases in climate models. Journal of Climate, 26 (10), 3258-3274. doi: https://doi.org/10.1175/JCLI-D-12-00429.1

Wood, R. (2012). Stratocumulus clouds. Monthly Weather Review, 140(8), 23732423. doi: https://doi.org/10.1175/MWR-D-11-00121.1

Wood, R., Bretherton, C. S., Leon, D., Clarke, A. D., Zuidema, P., Allen, G., \& Coe, H. (2011). An aircraft case study of the spatial transition from closed to open mesoscale cellular convection over the Southeast Pacific. Atmospheric Chemistry and Physics, 11(5), 2341-2370. doi: https://doi.org/10.5194/ 
acp-11-2341-2011

Wood, R., \& Hartmann, D. L. (2006). Spatial variability of liquid water path in marine low cloud: The importance of mesoscale cellular convection. Journal of Climate, 19(9), 1748-1764. doi: https://doi.org/10.1175/JCLI3702.1

Yamaguchi, T., \& Feingold, G. (2015). On the relationship between open cellular convective cloud patterns and the spatial distribution of precipitation. Atmospheric Chemistry and Physics, 15(3), 1237-1251. doi: https://doi.org/10 $.5194 /$ acp-15-1237-2015

Yin, B., \& Albrecht, B. A. (2000). Spatial variability of atmospheric boundary layer structure over the eastern equatorial Pacific. Journal of Climate, 13(9), 1574-1592. doi: \{https://doi.org/10.1175/1520-0442(2000)013〈1574:SVOABL $\rangle 2$ $.0 . \mathrm{CO} ; 2\}$

Zhou, X., Ackerman, A. S., Fridlind, A. M., \& Kollias, P. (2018). Simulation of mesoscale cellular convection in marine stratocumulus. part i: Drizzling conditions. Journal of the Atmospheric Sciences, 75(1), 257-274. doi: https://doi.org/10.1175/JAS-D-17-0070.1

Zuidema, P., Li, Z., Hill, R. J., Bariteau, L., Rilling, B., Fairall, C., ... Hare, J. (2012). On trade wind cumulus cold pools. Journal of the Atmospheric Sciences, 69(1), 258-280. doi: https://doi.org/10.1175/JAS-D-11-0143.1 